\title{
Coordinated control of senescence by IncRNA and a novel T-box3 co-repressor complex
}

\section{Pavan Kumar $\mathbf{P}^{1,2}$, Uchenna Emechebe ${ }^{3 \dagger}$, Richard Smith ${ }^{4 \dagger}$, Sarah Franklin ${ }^{5,6}$, Barry Moore7, Mark Yandell7, Stephen L Lessnick ${ }^{2,4,8}$, Anne M Moon ${ }^{1,2,7 *}$}

${ }^{1}$ Weis Center for Research, Geisinger Clinic, Danville, United States; ${ }^{2}$ Department of Pediatrics, University of Utah, Salt Lake City, United States; ${ }^{3}$ Department of Neurobiology and Anatomy, University of Utah, Salt Lake City, United States; ${ }^{4}$ The Centre for Children's Cancer Research, Huntsman Cancer Institute, University of Utah, Salt Lake City, United States; ${ }^{5}$ Nora Eccles Harrison Cardiovascular Research and Training Institute, University of Utah, Salt Lake City, United States; ${ }^{6}$ Department of Internal Medicine, University of Utah, Salt Lake City, United States; ${ }^{7}$ Department of Human Genetics, University of Utah, Salt Lake City, United States; ${ }^{8}$ Department of Oncological Sciences, Huntsman Cancer Institute, University of Utah, Salt Lake City, United States

\begin{abstract}
Cellular senescence is a crucial tumor suppressor mechanism. We discovered a CAPERa/TBX3 repressor complex required to prevent senescence in primary cells and mouse embryos. Critical, previously unknown roles for CAPERa in controlling cell proliferation are manifest in an obligatory interaction with TBX3 to regulate chromatin structure and repress transcription of CDKN2A-p16 INK and the RB pathway. The IncRNA UCA1 is a direct target of CAPER $\alpha / T B X 3$ repression whose overexpression is sufficient to induce senescence. In proliferating cells, we found that hnRNPA1 binds and destabilizes CDKN2A-p16INK mRNA whereas during senescence, UCA1 sequesters hnRNPA1 and thus stabilizes CDKN2A-p16 ${ }^{I N K}$. Thus CAPERa/TBX3 and UCA1 constitute a coordinated, reinforcing mechanism to regulate both CDKN2A-p16 ${ }^{\text {INK }}$ transcription and mRNA stability. Dissociation of the CAPERa/TBX3 co-repressor during oncogenic stress activates UCA1, revealing a novel mechanism for oncogene-induced senescence. Our elucidation of CAPER $\alpha$ and UCA1 functions in vivo provides new insights into senescence induction, and the oncogenic and developmental properties of TBX3.
\end{abstract}

DOI: 10.7554/eLife.02805.001

\section{Introduction}

Senescence is defined as irreversible arrest of cell growth and loss of replicative capacity (Hayflick, 1965). Senescent cells have a large, flattened morphology and a characteristic secretory phenotype. They may be multinucleate, exhibit nuclear distortion, and contain senescence-associated heterochromatin foci (SAHFs) (Kosar et al., 2011). Senescence can be induced by various stimuli such as DNA damage, metabolic or oxidative stress, or expression of oncoproteins (Larsson, 2005; Kuilman et al., 2010; Coppé et al., 2011).

The p16/retinoblastoma protein (RB) and p53 tumor suppressor pathways are key regulators of senescence induction and maintenance in many cell types (Narita et al., 2003). p14 ARF-p53 activates $\mathrm{p} 21$, whereas the $\mathrm{p} 16^{\mathrm{INK} 4 \mathrm{a}}-\mathrm{RB}$ pathway culminates in E2F transcriptional target repression and senescence (DeGregori, 2004). Expression of CDKN2A-p14 ${ }^{A R F}$ and CDKN1A-p21 ${ }^{\text {IP }}$ is repressed by the related transcription factors TBX2 and TBX3; this is the postulated mechanism for senescence bypass 
eLife digest Cell division and growth are essential for survival. But it is equally important that cells can stop dividing, because failing to do so can lead to the uncontrolled tumor growth seen in cancer. One such quality control mechanism is called senescence, which stops the growth and multiplication of cells that are old, damaged or behaving in ways that may harm the organism. All cells eventually stop dividing and undergo senescence, but a number of factors may trigger the process early, such as DNA damage, stress or the appearance of cancer-causing proteins.

Senescence can be harmful if it occurs too early in life and interferes with normal growth. Severe birth defects-including fatal heart problems and limb malformations-occur if senescence is inappropriately triggered early in development. Mutations in a gene encoding a protein called TBX3 have been linked to these severe birth defects.

Normally, TBX3 stops the production of other proteins that trigger senescence in early development, and helps to maintain stable conditions in adult cells. Understanding how it does so could help scientists understand normal cell function and aging, and also help to find ways to trigger senescence in cancerous cells.

Kumar et al. found that a protein called CAPERa-for short Coactivator of AP1 and Estrogen Receptor-forms a complex with TBX3 that stops cells dividing in living organisms in at least two different ways. One way is by altering how DNA is folded. The other way involves a non-coding strand of RNA from a gene called UCA1: this RNA prevents the degradation of proteins that stop cell division.

In normal proliferating cells, the CAPERa/TBX3 protein complex prevents the production of UCA1 RNA. In contrast, in cells that received a cancer causing stimulus, TBX3 and CAPER $\alpha$ physically separate: this activates production of UCA1 RNA and causes senescence. Further studies will be required to establish exactly how the CAPERa/TBX3 protein complex interacts with DNA and RNA to control senescence and prevent cancer.

DOI: 10.7554/eLife.02805.002

of Bmi1-/- and SV40 transformed mouse embryonic fibroblasts by overexpressed TBX2 and TBX3, respectively (Jacobs et al., 2000; Brummelkamp et al., 2002; Prince et al., 2004).

Mutations in human TBX3 cause a constellation of severe birth defects called ulnar-mammary syndrome (Bamshad et al., 1997). Efforts to understand the molecular biogenesis of this developmental disorder uncovered additional functions for TBX3 beyond transcriptional repression (Fan et al., 2009; Frank et al., 2013; Kumar et al., 2014) as well as critical roles in adult tissue homeostasis (Frank et al., 2012). The pleiotropic effects of TBX3 gain and loss of function suggest its molecular activities are context and cofactor dependent.

Despite the biologic importance of TBX3, few interacting proteins or target genes have been discovered, and the mechanisms underlying its regulation of cell fate, cell cycle, and carcinogenesis are obscure. We found that TBX3 associates with CAPER $\alpha$ (Coactivator of AP1 and Estrogen Receptor), a protein identified in a liver cirrhosis patient who developed hepatocellular carcinoma (Imai et al., 1993). CAPERa regulates hormone responsive expression and alternative splicing of minigene reporters in vitro (Jung et al., 2002; Dowhan et al., 2005) but its in vivo functions are unknown.

We show that a CAPER $/$ TBX3 repressor complex is required to prevent premature senescence of primary cells and regulates the activity of core senescence pathways in mouse embryos. We discovered co-regulated targets of this complex in vivo and during oncogene-induced senescence (OIS), including a novel tumor suppressor, the InCRNA UCA1. UCA1 is sufficient to induce senescence and does so in part by sequestering hnRNP A1 to specifically stabilize CDKN2A-p16 $6^{\text {INK }}$ mRNA. Our finding that CAPERa/TBX3 regulates $p 16$ levels by dual, reinforcing mechanisms position CAPERa/TBX3 and UCA 1 upstream of multiple members of the P16/RB pathway in the regulatory hierarchy that controls cell proliferation, fate and senescence.

\section{Results}

\section{CAPER $\alpha$ interacts with TBX3 in vivo}

We recently discovered that TBX3 (human) and Tbx3 (mouse) interact with RNA-binding and splicing factors (Kumar et al., 2014). Among these, mass spectrometry of anti-TBX3 immunoprecipitated 
(IP'd) proteins identified CAPERa (Figure 1A). Since TBX3 functions in mammary development and may contribute to the pathogenesis of breast and other hormone responsive cancers (Douglas and Papaioannou, 2013), its interaction with an ERa co-activator drove further investigation.

To determine if Tbx3 and Capera interact in vivo, we IP' $d$ endogenous Capera from embryonic day (e) 10.5 mouse embryo lysates (Figure 1B). Immunoblotting for Tbx3 confirmed its interaction with Capera (Figure 1C, lane 5) and in vitro pull down assays revealed that their interaction is direct (Figure 1D, lane 6). Capera is very broadly expressed during mouse embryonic development (Moon, unpublished), whereas Tbx3 expression is very tissue specific and dynamic. We thus questioned whether the endogenous proteins interact in mouse tissues relevant to malformations seen in humans with UMS. Immunohistochemistry on sectioned e10.5 embryos showed that Tbx3 and Capera proteins are co-expressed and have distinct localization patterns in different tissues: Capera is detected in all dorsal root ganglia nuclei (Figure 1E), some of which contain co-localized Tbx3; in proximal limb mesenchyme, Tbx3 and Capera co-localize in nuclei (Figure 1F) while in some distal cells and the ectoderm, Capera is nuclear and Tbx3 is cytoplasmic (Figure 1G, white arrowheads). Such tissue specificity suggests that functions of the Capera/Tbx3 complex are context dependent.

TBX3 DNA binding and repressor domains (DBD, RD) independently mediate interactions with partner proteins (Carlson et al., 2001; Coll et al., 2002; Kumar et al., 2014). To identify domains required for CAPERa interaction, we used a series of overexpression plasmids encoding mouse Tbx3 proteins with different mutations and functional domains (Figure $1 \mathrm{H}$ ). The DBD, deleted repressor domain $(\triangle \mathrm{RD})$ and exon7 missense mutants are untagged proteins, whereas the $\mathrm{C}$-terminal deletion mutants are Myc-tagged.

To assay the interactions of the untagged exogenous proteins with endogenous CAPERa in HEK293 cells, we needed to knockdown endogenous TBX3 with shRNA (Figure 11). We previously demonstrated that mutant Tbx3 proteins produced from the overexpression plasmids are present in TBX3 knockdown HEK293 cells (Figure 2 in Kumar et al. 2014). CAPERa is present and can be IP'd in the context of knockdown of endogenous TBX3 and subsequent overexpression of mutant mouse Tbx3 proteins (Figure 1J). Immunoblot of anti-CAPERa IP'd samples shows that the endogenous CAPERa interacts with Tbx3 DBD mutant proteins (Figure 1J', lanes 2 and 3 are L143P and N227D, respectively).

The Tbx3 deletion constructs encode Myc- tagged mutants that can be distinguished from endogenous TBX3, so interactions were assayed in wild-type HEK293 cells. Myc-tagged deletion mutants are IP' $d$ by the anti-Myc antibody (Figure $1 K$ ), and probing anti-Myc IP' $d$ material for CAPERa reveals that deletions more proximal than amino acid 655 disrupt the CAPERa/Tbx3 interaction (Figure $1 K^{\prime}$ ).

The observation that deletions of the Tbx3 C-terminus disrupt the CAPERa/Tbx3 interaction led us to test whether the $\mathrm{C}$-terminal repressor domain, which is crucial for the ability of Tbx3 to function as a transcriptional repressor and immortalize fibroblasts (Carlson et al., 2001), plays a role. Although the untagged $\triangle R D$ mutant is produced in TBX3 shRNA knockdown cells and IP'd by the anti-Tbx3 antibody (Figure $1 \mathrm{~L}$ and Kumar et al., 2014) it does not interact with CAPERa (Figure 1 1'). CAPERa also fails to interact with a $\mathrm{C}$-terminal Tbx3 frameshift mutant similar to one identified in humans with UMS (Bamshad et al., 1999) (Figure 1-figure supplement 1).

\section{CAPER $\alpha$ and TBX3 are required to prevent premature senescence of primary human and mouse cells}

Roles for TBX3 in cell cycle regulation and senescence of primary cells have not been reported. We employed loss-of-function to test whether TBX3 is required for sustained proliferation of primary cultured human foreskin fibroblasts (HFFs) and to determine if CAPERa functions in this process. We tested two different CAPERa and TBX3 shRNAs (please see 'Materials and methods' for sequences and location in target mRNAs). Both CAPERa and TBX3 shRNAs effectively decreased the amount of CAPERa mRNA (Figure 2-figure supplements $1 A$ and 2A,B). Knockdown of either protein resulted in a dramatic increase in senescence associated $\beta$-galatosidase activity (SA- $\beta$ gal, Figure 2A-D; Figure 2-figure supplements 1 and $2 \mathrm{C}-\mathrm{H}$ ). This effect is specific because it occurs with two different shRNAs and is rescued by overexpression of CAPERa (Figure 2-figure supplement 1B,E,G,H) and Tbx3 (Figure2-figure supplement 2B,E,G,H). For all subsequent experiments, CAPERa shRNA 'A' and TBX3 shRNA 'A' were used to perform knockdown (KD) in HFFs (protein knockdowns are shown in Figure 2-figure supplements 1 and 2, I panels).

The effects of CAPER and TBX3 KD on HFF cell growth, and SA- $\beta$ gal activity suggest induction of premature senescence. Consistent with this, both KDs dramatically influenced nuclear structure, 

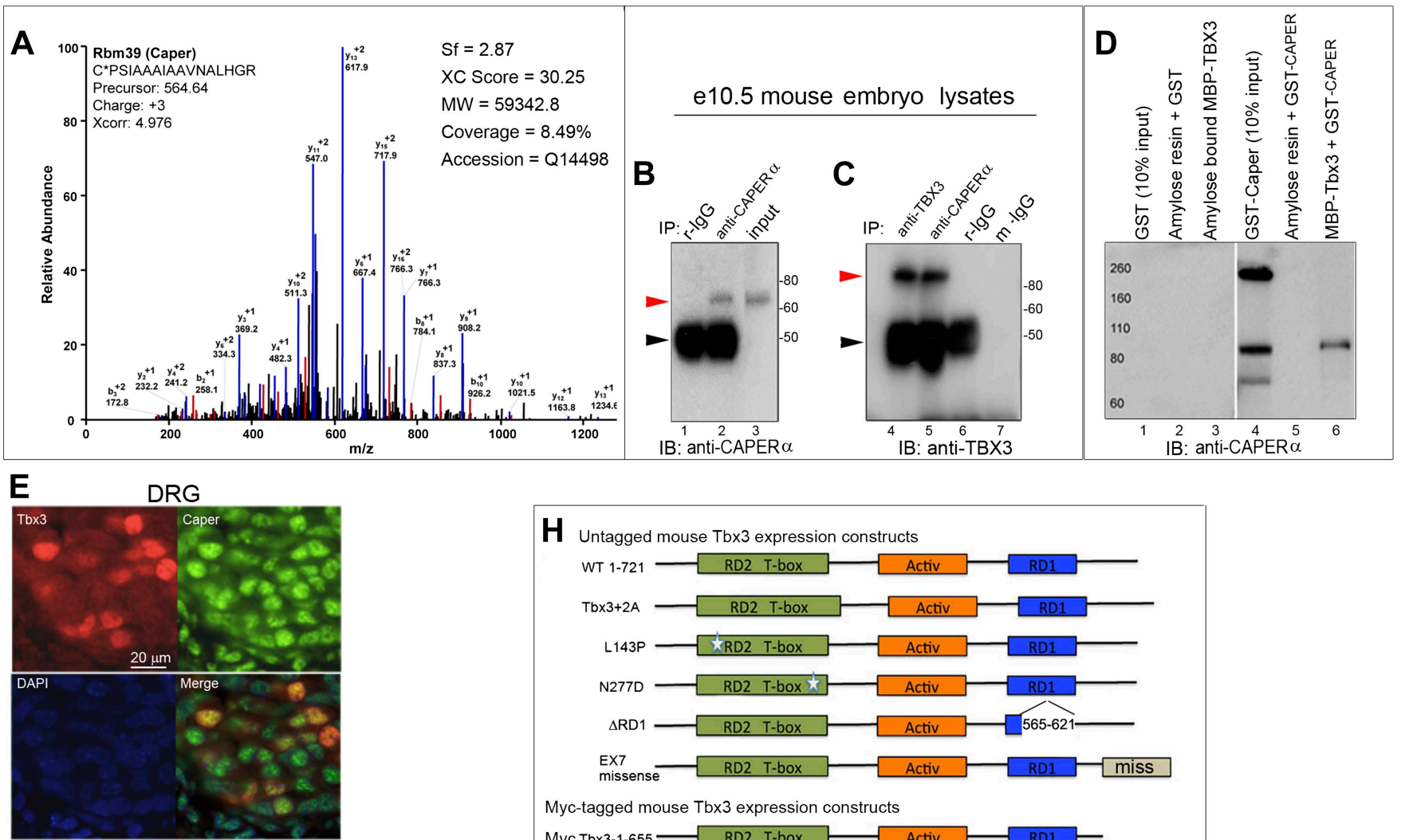

F prox limb bud

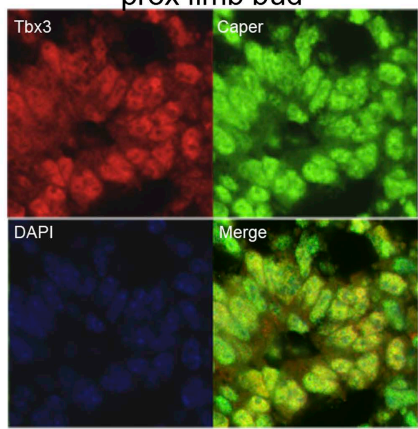

G

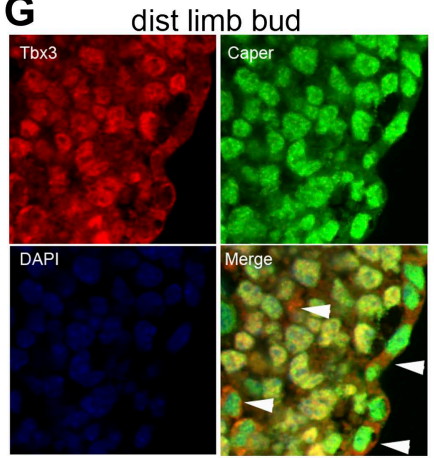

H Untagged mouse Tbx3 expression constructs

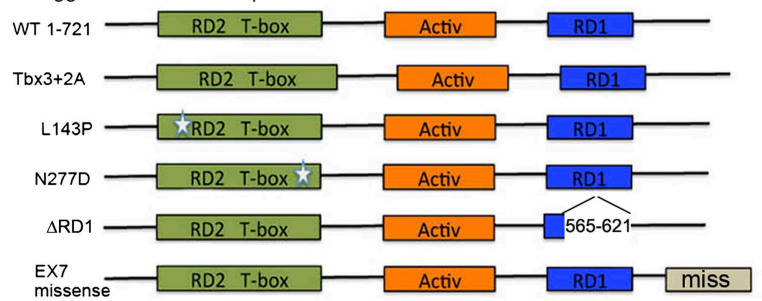

Myc-tagged mouse Tbx3 expression constructs

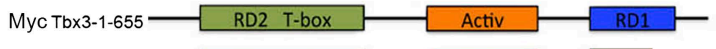

Myc Tbx3-1-623 RD2 T-box Activ RD1

Myc Tbx3-1-565 RD2 T-box Activ

Myc Tbx3-1-470 RD2 T-box

Myc Tbx3-1-437 RD2 T-box Activ

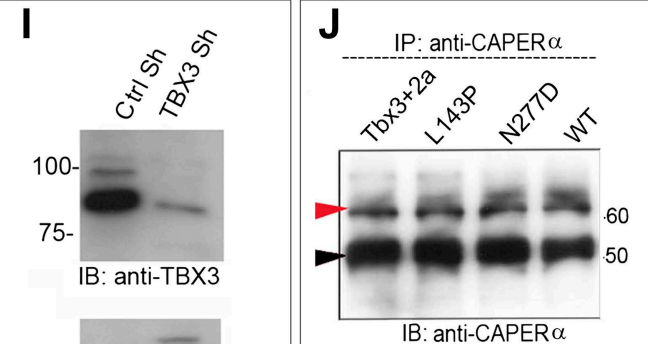

$50-$

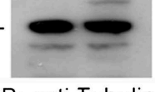

IB: anti-Tubulin

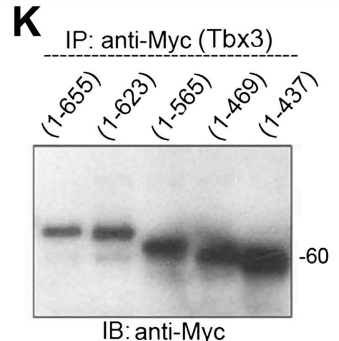

K'

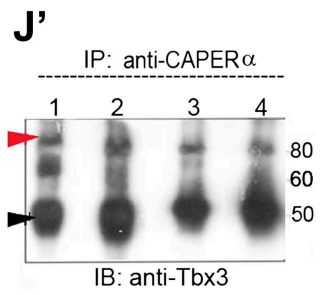

750 aa

L IP: anti-Tbx3
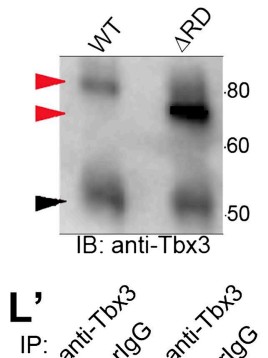

IP: anti-Myc (Tbx3)

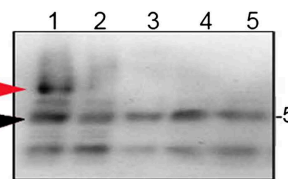

IB: anti-CAPER $\alpha$

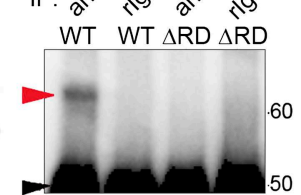

IB: anti-CAPER $\alpha$

Figure 1. CAPERa and TBX3 directly interact via the TBX3 repressor domain. (A) Representative spectrum for CAPERa identified in anti-TBX3 co-IP of HEK293 cell lysates. Mass spec analysis identified six specific CAPERa peptides, providing $8.5 \%$ sequence coverage of the protein. This spectrum shows fragmentation of one of these peptides, C*PSIAAAIAAVNALHGR, with diagnostic b-and y-series ions shown in red and blue, respectively. * indicates Figure 1. Continued on next page 
Figure 1. Continued

carbamidomethylation. (B) Anti-CAPERa immunoblot (IB) analysis of anti-CAPERa immunoprecipitated (IP'd, lane 2) e10.5 mouse embryo lysates. Black arrowheads indicate IgG heavy chain and red indicate protein of interest (CAPERa or TBX3). (C) Anti-Tbx3 IB of anti-Tbx3 (lane 4) and anti-Capera (lane 5) IP'd mouse embryo lysates. Rabbit (r)-lgG (lanes1, 6) and mouse (m)-lgG (lane 7) are negative controls. (D) In vitro MBP pull down assay: MBP and MBP-Tbx3 bound amylose affinity columns were incubated with GST or GST-CAPERa. Bound proteins were eluted, subjected to SDS-PAGE followed by IB with anti-CAPERa antibody. (E-G) Colocalization of Tbx3 and Capera in vivo shown by immunohistochemical analysis of sectioned e10.5 mouse embryo: embryonic dorsal root ganglion (DRG, E), proximal (F), and distal (G) limb bud with anti-Tbx3 (red) and anti-Capera (green) antibodies and DAPI (blue). White arrowheads in G label representative ectodermal and mesenchymal cells with cytoplasmic Tbx3 and nuclear Capera. (H) Schematic representation of mouse Tbx3 overexpression constructs. Tbx3 DNA binding domain (DBD) point, $\triangle R D$ and exon7 missense proteins are untagged and the C-terminal deletion mutants are Myc-tagged. (I) Anti-TBX3 IB of HEK293 cell lysates transfected with control or anti-TBX3 shRNA. (J) Anti-CAPERa IB of anti-CAPERa IP'd samples from HEK293 cells transfected with anti-TBX3 shRNA and expressing mouse Tbx3 proteins listed at top. Production and IP of endogenous CAPERa is not affected by production of mutant Tbx3 proteins. ( $\mathbf{J}^{\prime}$ ) Anti-Tbx3 IB of anti-CAPERa IP'd samples from HEK293 cells transfected with anti-TBX3 shRNA and expressing Tbx3 proteins as in $\mathbf{J}$. The DBD point mutant proteins (lanes 2,3 ) interact with CAPERa as efficiently as wild type Tbx3 (lanes 1, 4). (K) Anti-Myc IB of anti-Myc IP'd samples from HEK293 cell lysates expressing Myc-tagged mouse Tbx3 C-terminal deletion mutants. The mutant proteins are expressed and efficiently IP'd. These cells were not treated with anti-TBX3 shRNA because the expression constructs produce a Myc- tagged mutants that can be IP'd independently of endogenous TBX3. (K') anti-CAPERa IB of anti-Myc IP'd samples from HEK293 cell lysates expressing Myc-tagged mouse Tbx3 C-terminal deletion mutants. These cells were not treated with anti-TBX3 shRNA because the expression constructs produce a Myc- tagged mutants that can be IP'd independently of endogenous TBX3. (L) Anti-Tbx3 IB of anti-Tbx3 IP'd samples from HEK293 cells transfected with anti-TBX3 shRNA and expressing wt or repressor domain deletion mutant $(\triangle \mathrm{RD})$ mouseTbx3. The shRNA does not prevent production of the overexpression proteins. (L') Anti-CAPERa IB of HEK293 cells transfected with anti-TBX3 shRNA and expressing mouse wt or $\triangle R D$ Tbx3 proteins and IP' $\mathrm{d}$ with anti-Tbx3 or IgG. Loss of the repressor domain prevents interaction with CAPERa. Black arrowheads indicate IgG heavy chain and red indicate protein of interest (CAPERa or TBX3). TBX3, CAPER $=$ human; Tbx3, Capera = mouse.

DOI: 10.7554/eLife.02805.003

The following figure supplements are available for figure 1:

Figure supplement 1. Missense mutation of the C-terminus of Tbx3 disrupts interaction with CAPERa.

DOI: 10.7554/eLife.02805.004

chromatin organization and formation of SAHFs (Figure 2G-J). Expression of senescence mediators was increased and conversely, expression of cell growth and cell cycle promoting genes was similarly decreased by CAPERa and TBX3 KD (Figure 2K-M). Increased expression of CDKN2A-p16 ${ }^{\text {INK }}$ (henceforth referred to as $p 16^{I N K}$ ) and decreased PCNA, E2F1 and 2, CDK2, CDK4, CDC2 transcripts indicate that CAPERa/TBX3 represses the p16/RB pathway in proliferating HFFs. PMAIP1, CDKN1A-p21, and other p53 pathway members were also increased. Collectively, these data indicate that CAPER $a$ and TBX3 are required to prevent senescence of primary HFFs and act upstream of major cell cycle and senescence regulatory pathways.

\section{Tbx3 null murine embryonic fibroblasts undergo p16/RB-mediated premature senescence, Caper $\alpha$ mislocalization and nuclear disruption}

Tbx3 deficiency in mice causes lethal embryonic arrhythmias and limb defects however, these phenotypes are not due to increased apoptosis (Frank et al., 2012 and Emechebe and Moon, unpublished). We hypothesized that Tbx3 may prevent senescence of embryonic cells, and so examined murine embryonic fibroblasts (MEFs) from e13.5 wild type (WT) and Tbx3 null (-/-) embryos. WT MEFs undergo 10 passages with regular, $20 \mathrm{hr}$ doubling times. In contrast, Tbx3-/- MEFs had increased SA-Bgal activity and ceased proliferating after only four passages (Figure $2 \mathrm{~N}-\mathrm{Q}$ ). Most Tbx3-/- MEFs had distorted or ruptured nuclei (Figure 2-figure supplement 3A-C) and lamin $\beta 1$ staining was already altered at passage 1 (Figure 2-figure supplement 3B'). Capera null mutant embryos do not survive long enough to generate MEFs for complementary experiments (Emechebe and Moon, unpublished) however, Capera localization is markedly abnormal in Tbx3-/- MEFS after only 1 passage (Figure 2-figure supplement 3D-F'). These data suggest that Tbx3 is required for preservation of nuclear architecture and to tether Capera in its normal nuclear domains in proliferating cells.

Consistent with premature senescence seen in Tbx3-/- MEFs, key pro-senescence pathways are activated after loss of Tbx3 in vivo: in protein lysates from Tbx3-/- embryos, RB was hypophosphorylated on multiple serine residues, consistent with increased p16 and decreased Cdk2 and Cdk4 protein levels relative to control (Figure 2R). The levels of p21 and other senescence markers were increased, while numerous Cyclins and other Cdks were decreased (Figure 2R, Figure 2-figure supplement 3G). All of these findings are consistent with a requirement for Tbx3 to prevent senescence in embryonic mice and MEFs. 

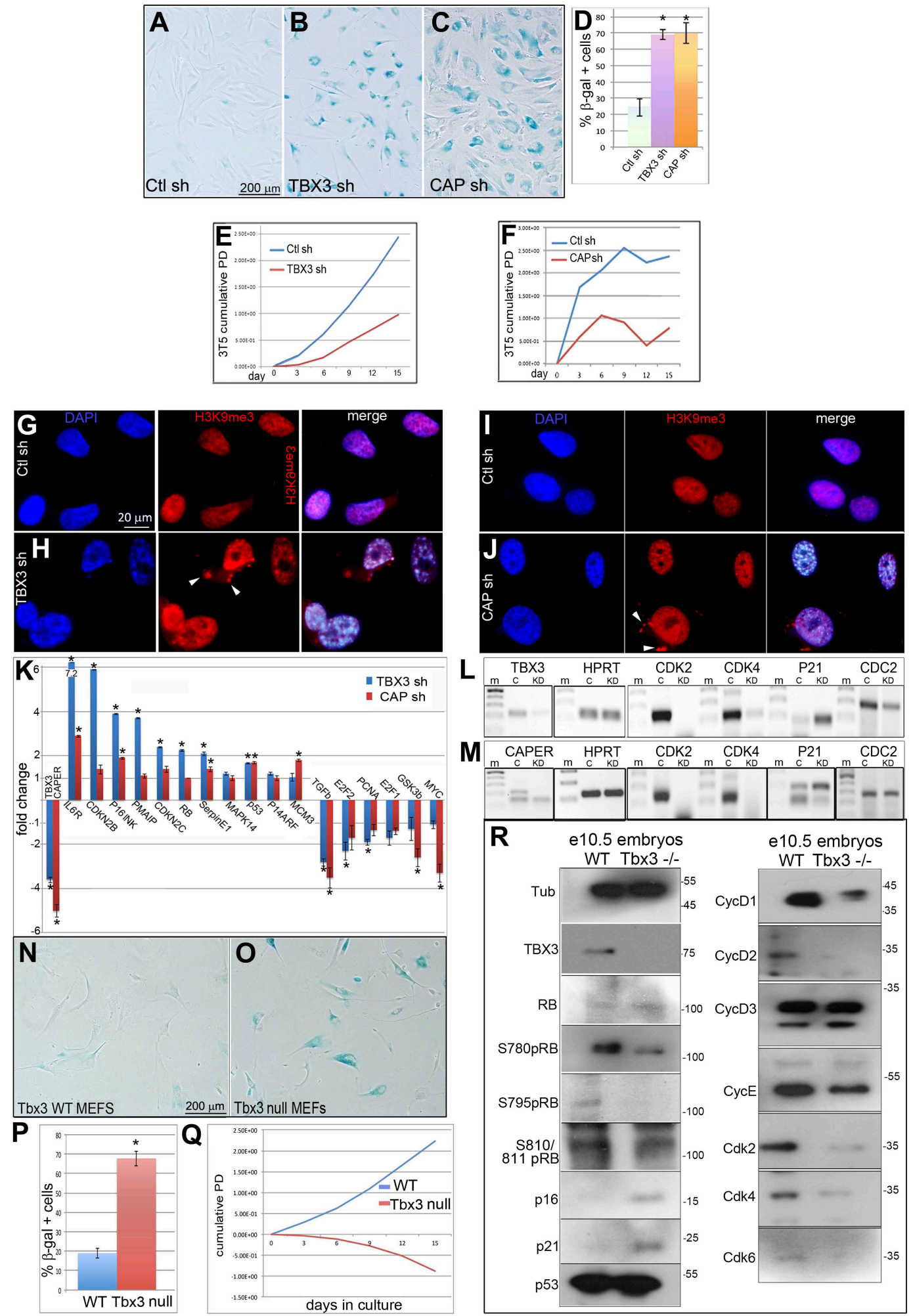

Figure 2. Knockdown of endogenous CAPER $\alpha$ and TBX3 in primary human fibroblasts and mouse embryos induces premature senescence and disrupts expression of cell cycle and senescence regulators. (A-C) Representative bright field images of senescence associated $\beta$-galactosidase (SA- $\beta G$ ) assays of HFFs transduced with control, TBX3 shRNA A or CAPER $\alpha$ shRNA A. Only occasional cells in the control transduction have detectable lacZ staining (blue) Figure 2. Continued on next page 
Figure 2. Continued

whereas knockdown of either TBX3 or CAPERa results in marked changes in cell morphology and increased lacZ staining. (D) Bar graph quantitating $\%$ beta-galactosidase positive cells from four replicate plates of SA- $\beta$ gal assays. * indicates $p<0.001$ compared to control. (E and F) $3 T 5$ cell proliferation assay (Lessnick et al., 2002) of cumulative population doublings in HFFs transduced at passage 30 with control, TBX3 or CAPERa shRNAs. These are representative curves of duplicate experiments; each point on the curve is a measurement of cell count from a single plating followed over the course of the experiment as described in methods. (G-J) Immunohistochemical analysis of H3K9me3 immunoreactivity (red) and DAPI (blue) in HFFs after knockdown with control (G and I), TBX3 (H), or CAPERa (J) shRNAs. Individual channels are shown and the merged image is on the right. Note increased nuclear punctate staining consistent with Senescence-associated heterochromatin foci (SAHFs) in both channels and evidence of nuclear disruption (white arrowheads in red channel) after loss of either TBX3 or CAPERa. (K-M) Analysis of cell cycle and senescence marker transcript levels in HFFs transduced with control, TBX3, or CAPERa shRNAs. (K) Relative transcript levels assessed by quantitative real time-PCR (qPCR) of cDNA. Values reflect fold change in knockdown HFFs relative to control after normalization to HPRT levels. Note general pattern of expression changes are similar in TBX3 (blue) and CAPERa (red) knockdowns. Data are plotted as fold change mean \pm standard deviation. * indicates $p<0.05$ relative to control. (L and $\mathbf{M})$ Agarose gel of PCR amplicons of cDNAs reverse transcribed from TBX3 (L) or CAPERa (M) shRNA knockdown HFF RNA reveals similar decreases in cell cycle promoting genes CDK2 and 4 in TBX3 and CAPERa knockdowns and increased p21 levels. (N and $\mathbf{O}$ ) SA- $\beta$ gal assay of wild type and Tbx3 null MEFS reveals that Tbx3 is required to prevent premature senescence of primary murine embryonic fibroblasts (MEFs). (P) Quantitation of \% betagalactosidase positive cells from five replicate experiments exemplified in $\mathrm{O}, \mathrm{P}$. * indicates $\mathrm{p}<0.01$. (Q) 3 T5 cell proliferation assay of cumulative population doublings in wild-type and Tbx3 null MEFs. These are representative curves from duplicate experiments; each point on the curve is a measurement of cell count from a single plating followed over the course of the experiment as described in 'Materials and methods'. (R) IBs to assay levels of cell cycle and senescence proteins in wild type and Tbx3 null embryo lysates. Tubulin loading control is at top left (Tub). The changes at the protein level correlate with those observed at the RNA level $(\mathbf{K}-\mathbf{M})$ and RB is hypophosphorylated on multiple serine residues consistent with increased p16 and decreased CDK activity. TBX3, CAPER $=$ human; Tbx3, Capera $=$ mouse.

DOI: 10.7554/eLife.02805.005

The following figure supplements are available for figure 2:

Figure supplement 1. Effective knockdown of endogenous CAPERa in primary human foreskin fibroblasts using viral shRNA transduction. DOI: 10.7554/eLife.02805.006

Figure supplement 2. Effective knockdown of endogenous TBX3 in primary human foreskin fibroblasts using viral shRNA transduction. DOI: 10.7554/eLife.02805.007

Figure supplement 3. Tbx3 null murine embryonic fibroblasts (MEFS) have altered lamin $\beta 1$ localization, nuclear disruption and mislocalized Capera. DOI: 10.7554/eLife.02805.008

Previous studies have suggested that overexpression of TBX3 permits senescence bypass by directly repressing CDKN2A-p14 ${ }^{A R F}$ ( $p 14^{A R F}$ ) to activate p53 (Brummelkamp et al., 2002), but a role for TBX3 in regulating $p 16^{I N K}$ and the RB pathway has not been demonstrated. Thus, we expected that loss of p53 would rescue senescence resulting from TBX3 or CAPER $\alpha$ KD. To test this, we transduced TBX3 and CAPER $\alpha$ KD HFFs with shRNA to p53 (Masutomi et al., 2003) and assayed SA- $\beta$ gal activity and growth. Surprisingly, although p53 shRNA effectively decreased p53 (Figure 3-figure supplement 1A), it did not rescue SA- $\beta$ gal activity or growth arrest due to absence of TBX3 or CAPER $\alpha$ (Figure 3B,E, G,H). In contrast, shRNA-mediated KD of either RB (Boehm et al., 2005) or p16 (Haga et al., 2007) (Figure 3-figure supplement 1B,C) rescued these phenotypes in TBX3 and CAPER $\alpha$ KD cells (Figure 3C, $F-H, I-N$ ). These rescue experiments demonstrate that the $\mathrm{p} 16 / \mathrm{RB}$ pathway mediates senescence downstream of CAPER $\alpha$ and TBX3 loss-of-function in primary cells.

\section{CAPERa/TBX3 regulates chromatin status of the $p 16^{I N K}$ promoter}

Increased p16 protein and RB hypophosphorylation in Tbx3-/- embryos and p16/RB-mediated senescence after CAPER $\alpha$ and TBX3 KD could result from loss of direct repression of $p 16^{\text {INK }}$ by CAPER $\alpha /$ TBX3 in proliferating cells. We screened 7 amplicons spanning $\sim 6 \mathrm{~kb}$ upstream of $p 16^{\text {INK }}$ by ChIP-PCR of HFF chromatin (Figure 3-figure supplement 2); 3 amplicons were bound by CAPER $\alpha$ and TBX3 (Figure 30, lanes 7, 10). Loss of either protein decreased the heterochromatic marks H3K9me3 (Figure 30, lanes 14, 15) and H3K27me3 (Figure 3-figure supplement 3) and increased the euchromatic mark H3K4me3 (Figure 30, lanes 17, 18). Notably, less CAPER $\alpha$ occupied p16 $6^{\text {INK }}$ elements after TBX3 KD (Figure 30, lanes 11) while the amount of TBX3 bound post-CAPER $\alpha$ KD was comparable to control (Figure 30, lanes 9 vs 7). This is consistent with the abnormal localization of CAPER $\alpha$ seen in Tbx3-/- MEFS (Figure 2-figure supplement 3D'-F') and indicates that CAPER $\alpha$ requires TBX3 to occupy $p 16^{I N K}$ regulatory chromatin.

We examined whether CAPERa and/or TBX3 associate with promoters of other cell cycle genes that are transcriptionally dysregulated after CAPERa/TBX3 loss-of-function (Figure 2K-M). Antibodies against TBX3 and CAPER $\alpha$ ChIP'd the p14 ${ }^{A R F}$ initiator (Lingbeek et al., 2002) (Figure 3-figure supplement 4A); 


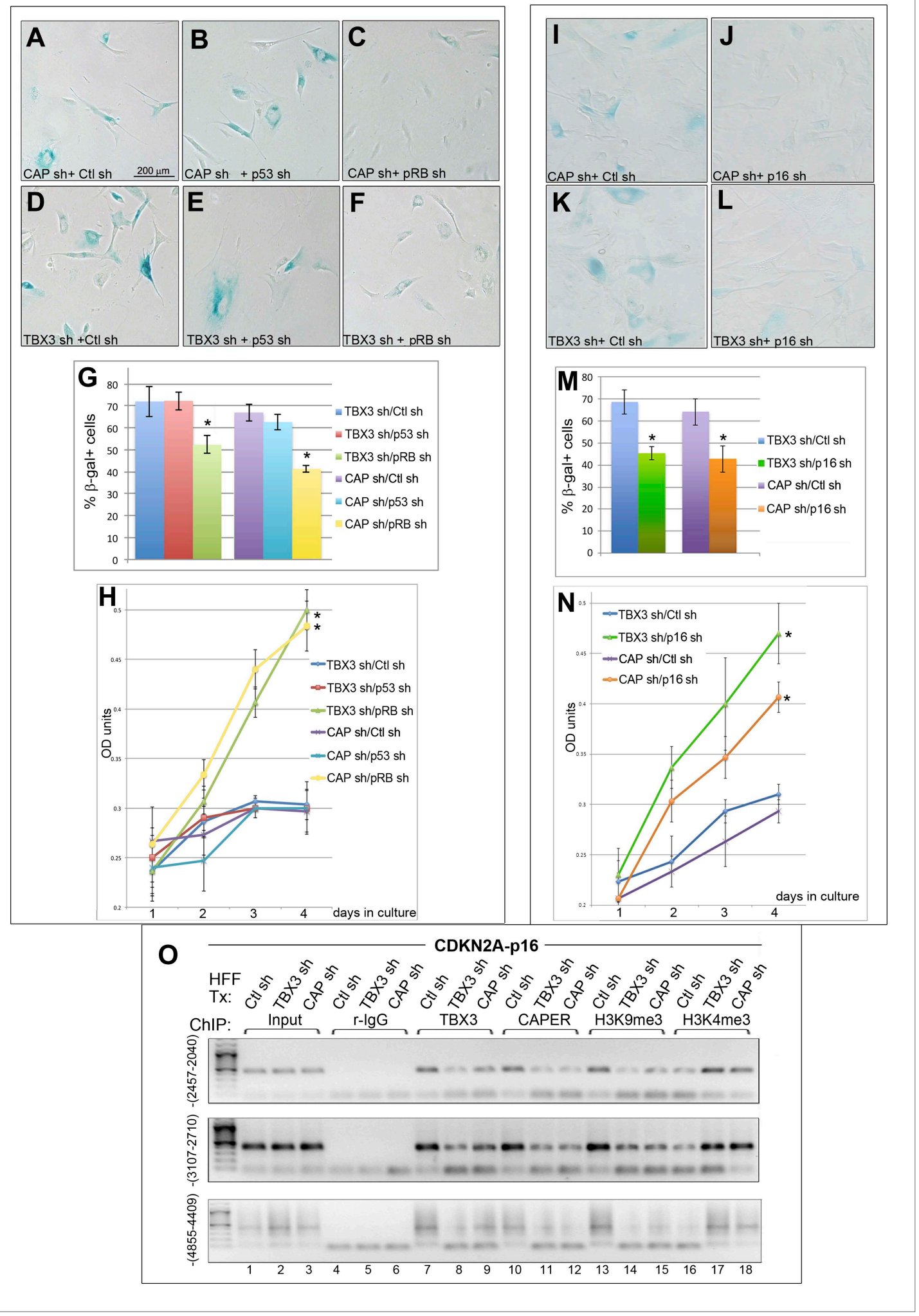

Figure 3. RB and p16 mediate senescence after CAPERa/TBX3 loss of function and CAPERa/TBX3 regulates chromatin structure of CDKN2A-p16. (A-F) SA-Bgal assays of HFFs stably transduced with control (Ctl) or p53 (Masutomi et al., 2003) or RB (Boehm et al., 2005) shRNAs subsequently transduced with CAPERa or TBX3 shRNAs. (G) \% Quantitation of $\mathbf{A}-\mathbf{F}$ from three replicate experiments. * indicates $\mathrm{p}<0.05$ relative to Control or p53 shRNAs. (H) Cell proliferation assayed by crystal violet incorporation (OD units) in HFFs treated as in $\mathbf{A}-\mathbf{F}$. * indicates $\mathrm{p}<0.001$ relative to $\mathrm{Ctl}$ or p53 shRNAs. (I-L) SA- $\beta$ gal Figure 3. Continued on next page 
Figure 3. Continued

assays of HFFs stably transduced with control or p16 (Haga et al., 2007) shRNAs subsequently transduced with CAPERa or TBX3 shRNAs.

(M) \% Quantitation of I-L from three replicate experiments. * indicates $\mathrm{p}<0.05$ relative to CtI shRNA. (N) Cell proliferation assayed by crystal violet incorporation (OD units) in HFFs treated as in I-L. * indicates $\mathrm{p}<0.01$ relative to Ctl shRNA. (O) ChIP-PCR with antibodies listed at top on three regions upstream of the CDKN2A-p16 transcriptional start site (TSS); position relative to (TSS) is indicated in parentheses at left of panels. PCR of input material used for the ChIP is shown under 'Input'. The shRNA transduced is listed above each lane (HFF Tx). TBX3 knockdown decreases binding of TBX3 (lanes 8) and CAPERa (lanes 11) to all three regions. CAPERa knockdown has minimal effect on TBX3 binding (lanes 9). Knockdown of either TBX3 or CAPERa decreases the repressive chromatin mark H3K9me3 (lanes14, 15) and increases the activating chromatin mark H3K4me3 (lanes 17, 18). TBX3, CAPERa = human; Tbx3, Capera $=$ mouse.

DOI: 10.7554/eLife.02805.009

The following figure supplements are available for figure 3:

Figure supplement 1. Effective knockdown of p53, RB and p16 in HFFs.

DOI: 10.7554 /eLife.02805.010

Figure supplement 2. UCSC Genome Browser view of the CDKN2A locus and 5' regions screened for binding by CAPERa and TBX3. DOI: 10.7554/eLife.02805.011

Figure supplement 3. CDKN2a-p16 H3K27 trimethylation markedly decreases in HFFS after knockdown of CAPERa or TBX3 consistent with activation of CDKN2a-p16 expression.

DOI: $10.7554 /$ eLife.02805.012

Figure supplement 4. Testing CAPERa and TBX3 binding to $p 14, p 21, C D K 2, C D K 4$, and CDKN1B regulatory elements. DOl: 10.7554/eLife.02805.013

here too, TBX3 KD disrupted CAPERa binding (Figure 3-figure supplement 4A', red arrowhead). Neither CAPERa nor TBX3 associated with amplicons scanning $1.8 \mathrm{~kb}$ upstream of CDKN1A-p21 or elements reportedly bound by TBX2 or TBX3 in other cell types (Figure 3-figure supplement 4B) (Prince et alı, 2004; Saramaki et al., 2006; Hoogaars et al., 2008). Testing for association with known regulatory elements of CDK2, CDK4, CDKN1B was also negative (Figure 3-figure supplement 4C-E) (Baksh et al., 2002; Wang et al., 2005; Louie et al., 2010). These data indicate that in proliferating primary cells, CAPERa/TBX3 specifically and directly repress the CDKN2A locus by binding multiple regulatory sequence elements and regulating chromatin marks.

\section{Expression of the IncRNA UCA 1 is repressed by CAPER $\alpha / T B X 3$ and sufficient to drive senescence of primary cells}

To identify novel genes repressed by CAPER $\alpha / T B X 3$, we employed differential display to detect transcripts that increased in response to KD of TBX3 and CAPERa in HEK293 cells (Figure 4A-C). Although most transcripts were unaffected by either KD, or changes were not shared (Figure 4-figure supplement 1A), DUSP4 and UCA1 were upregulated (Figure 4D, Figure 4-figure supplement 1B). DUSP4 is known to regulate cell survival and tumor progression, and overexpression induces senescence downstream of RB/E2F (Torres et al., 2003; Wang et al,, 2007), thus placing CAPER $\alpha / T B X 3$ upstream of another p16/RB effector. Little is known about the function of the IncRNA UCA1 (Wang et al., 2006, 2008), so we investigated it further.

We found that shRNA KD of CAPER $\alpha$ or TBX3 in primary HFFS recapitulated the increase in UCA1 transcripts seen in HEK293 cells (Figure 4E-H). We then tested whether CAPERa/TBX3 directly control transcription of UCA1 by interacting with potential regulatory elements. Public ChIP data (http:// genome.ucsc.edu/) indicate that the $2 \mathrm{~kb}$ upstream of UCA1 may contain such elements. We assayed 3 amplicons in this region (Figure 4I: A1, A2, A3) by ChIP-PCR of TBX3 and CAPERa: only region A3 was bound (Figure $4 \mathrm{~J}, \mathrm{~K}$, lanes 18 , red arrowheads).

We next determined whether increased UCA1 expression in response to KD of CAPERa or TBX3 was associated with altered chromatin structure (as seen with p16 $16^{1 N K}$, Figure 30). UCA1/A3 is normally in a heterochromatin configuration in HFFs, with repressive marks $\mathrm{H} 3 \mathrm{~K} 9 \mathrm{me} 3$ and $\mathrm{H} 3 \mathrm{~K} 27 \mathrm{me} 3$ (Figure $4 \mathrm{~L}$, lanes 12,14) and little H3K4me3 (Figure 4L, lane 18). After TBX3 KD, activating chromatin marks replaced repressive ones (Figure $4 L$, lanes 13, 15 and 19) and markedly less CAPERa was bound (Figure 4L, lane 17, red arrowhead). CAPERa KD also led to loss of repressive marks on UCA1/ A3 (Figure 4M lanes 9, 16), although TBX3 remained bound (Figure 4M, lane 11, red arrowhead). Combined with previous findings, we conclude that: (1) TBX3 recruits CAPER $\alpha$ to UCA1/A3 chromatin, (2) TBX3 alone is insufficient to repress UCA1 and, (3) the default state of UCA1 in proliferating HFFs is repression conferred by CAPER $\alpha / T B X 3$. 


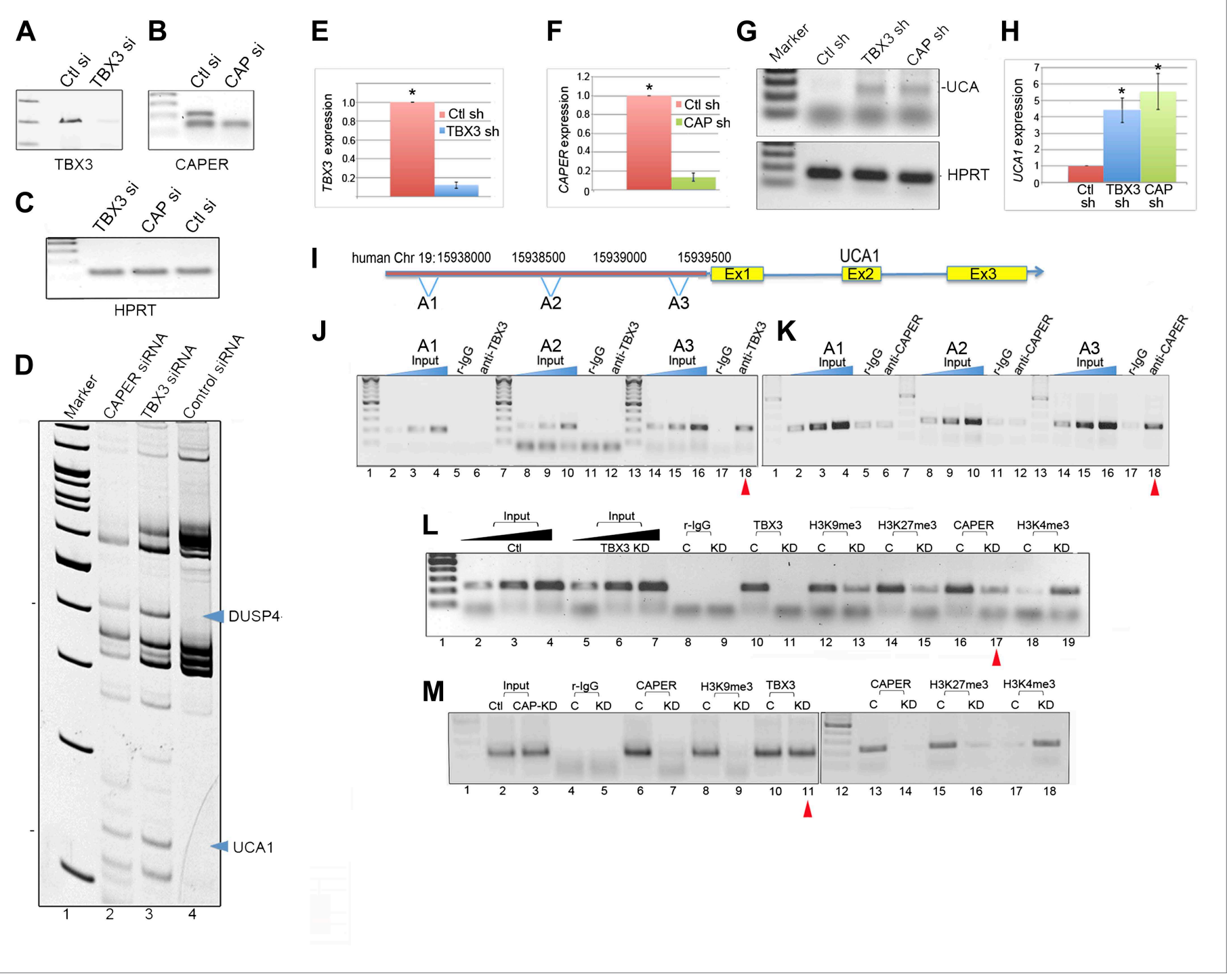

Figure 4. CAPERa/TBX3 directly represses expression of the long noncoding RNA UCA1. (A-C) Gel showing RT-PCR analysis of TBX3, CAPERa, and HPRT expression in control, TBX3 and CAPERa siRNA-transfected HEK293 cells. The siRNAs effectively decreased transcript levels of their targets. (D) Differential display: representative PAGE gel of cDNAs derived from random primed, RT-PCR'd mRNAs from CAPERa, TBX3 and control siRNA transfected HEK293 cells. Blue arrowheads denote upregulated transcripts subsequently identified by sequencing as DUSP4 and UCA1. (E and F) qPCR analysis of TBX3 and CAPER $\alpha$ transcript levels in control and TBX3 or CAPER $\alpha$ shRNA transduced HFFs (repeat of experiment shown in Figure 2-figure supplements 1A and 2A). (G) RT-PCR analysis of UCA1 and HPRT gene expression in control, TBX3 or CAPERa shRNA-transduced HFFs. (H) qPCR analysis of UCA1 transcript levels in control, TBX3 or CAPERa shRNA transduced HFFs. Results confirm differential display result that KD of TBX3 or CAPERa results in increase in UCA1 transcript levels. (I) Schematic representation of the UCA1 locus with primer sets employed for ChIP-PCR amplification of denoted regions $5^{\prime}$ of gene $(A 1, A 2, A 3)$. (J) Anti-TBX3 ChIP-PCR of regions of the UCA1 promoter in HFFs; only A3 is ChIP'd by TBX3 (lane 18, red arrowhead). (K) Anti-CAPERa ChIP-PCR of regions of the UCA1 promoter in HFFs; only A3 chromatin is ChIP'd (lane 18, red arrowhead). (L) ChIP-PCR analysis of UCA1/A3 chromatin from in HFFs transduced with control (C) or TBX3 (KD) shRNA; ChIP antibodies are listed at top. Note decreased CAPERa binding after TBX3 KD (lane 17, red arrowhead), gain of activating mark H3K4me3 and loss of repressive marks H3K9me3 and H3K27me3. (M) ChIP-PCR analysis of UCA1/A3 with antibodies listed at top of panel in HFFs transduced with control (C) or CAPERa shRNAs. Note continued TBX3 binding despite CAPERa KD (lane 11, red arrowhead) and changes in chromatin marks parallel those seen in with TBX3 KD in panel L. TBX3, CAPERa = human; Tbx3,

Capera $=$ mouse.

DOI: 10.7554/eLife.02805.014

The following figure supplements are available for figure 4:

Figure supplement 1. Validation of differential display findings.

DOI: 10.7554/eLife.02805.015 
UCA1 modulates behavior of bladder cancer cell lines (Wang et al., 2008), but there are no data on its function in primary cells; our results suggest that UCA1 may be involved in premature senescence. UCA 1 transcripts are low in proliferating HFFs, but 4 days after overexpression of UCA1 (Figure 5A), a robust SA- $\beta$ gal response is evident (Figure 5B-D). Cells constitutively expressing UCA1 ceased proliferating during selection and accumulated SAHFs (Figure 5E,F). Cell proliferation decreased in a UCA1 dosage-sensitive manner (Figure 5G-I), consistent with reduced levels of cell cycle promoting transcripts and increased levels of pro-senescence ones (Figure $5 \mathrm{~J}$ ). These transcriptional changes were manifest at the protein level (Figure 5-figure supplement 1). Premature senescence resulting from overexpression of UCA1 in HFFs reveals that this IncRNA is a novel regulator of cell proliferation and may function as a tumor suppressor in some contexts.

\section{Loss of UCA1 delays the onset of oncogene-induced senescence}

We tested the hypothesis that UCA1 is required for induction of oncogene-induced senescence (OIS) in primary cells ('RAS': HFFs transduced with constitutively active G12VRAS [Serrano et al., 1997]). There are markedly more UCA1 transcripts in RAS compared to presenescent 'PS' HFFs (Figure 5K). Knockdown of UCA 1 in RAS HFFs reduced SA- $\beta$ gal activity (Figure $5 \mathrm{~L}-\mathbf{Q}$ ) and improved RAS cell growth: the number of Ki67 + RAS cells was increased at days 3 and 6 after UCA1 KD (Figure 5R, $\mathrm{PO}$ and P1). However, by passage 2, the number of Ki67 + cells was not statistically different in UCA1 KD cells from control, despite persistently low levels of UCA1 (Figure 5S) and decreased levels of prosenescence transcripts (Figure 5T). Overall, this indicates that senescence can occur in the absence of high levels of UCA1 but that timely execution of the OIS program requires UCA1.

We next investigated whether increase in UCA1 transcripts in OIS is a manifestation of loss of CAPERa/TBX3 occupancy/repression of UCA1/A3. Indeed, the repressor dissociates from UCA1/A3 in RAS HFFs and UCA1/A3 chromatin switches from heterochromatic to euchromatic marks (Figure 5U). This is consistent with the senescence-inducing effects of CAPERa/TBX3 loss-of-function (Figure 2) and resulting upregulation of UCA1 (Figure 4), and establishes CAPERa/TBX3 regulation of UCA1 in an independent model of senescence.

\section{UCA1 promotes senescence by sequestering hnRNP A1 to stabilize p16 ${ }^{I N K}$ mRNA}

Some IncRNAs influence transcription by recruiting chromatin modifiers to target genes (Fatica and Bozzoni, 2014). We tested whether the increased levels of prosenescence transcripts occurring in response to UCA1 (Figure $5 \mathrm{~J}$ ) were the result activating chromatin changes however, ChIP-PCR assay for H3K9 acetylation of the $p 16^{I N K}, p 14^{A R F}, C D K N 1 A-p 21$ (and other) promoters did not reveal changes in this activating mark in response to UCA1 (Figure 5-figure supplement 2). We thus tested whether altered mRNA stability contributed to the observed changes. HFFs were transfected with UCA1 expression or control plasmid and after 2 days, treated with Actinomycin D. Total RNA was collected at 0-4 hr post-treatment and mRNA levels assayed using RT-PCR. Remarkably, overexpression of UCA1 resulted in the stabilization of mature $p 16^{I N K}, p 14^{A R F}, E 2 F 1$, and TGF 1 mRNAs: in the time frame examined, $p 16^{I N K}, p 14^{A R F}$, and E2F1 mRNAs do not decay and their $t_{1 / 2}$ values are therefore denoted as ' $n$ ' (no decay). The half-life estimates shown were calculated using linear regression; those best fit lines, their equations and $R$ values are shown in Figure 6-figure supplement 1. $t_{1 / 2}$ of $p 16^{\text {INK }}$ mRNA in control cells was $3.9 \mathrm{hr}$ vs $n$ in UCA1 overexpressing cells; $p 14^{A R F}, 2.4$ vs n; E2F1, 7.2 vs n; TGF 1 , 1.9 vs 2.9. In marked contrast, MYC, CDKN1A-p21, CDKN2D and RB mRNAs decayed at rates indistinguishable from control (Figure 6A; Figure 6-figure supplement 1). The effects of UCA1 overexpression on $p 16^{I N K}$ mRNA stability were confirmed by Northern blot (Figure 6-figure supplement 2).

Regulation of $p 16^{I N K}$ transcript stability is a critical mechanism for growth control (Wang et al., 2005; Chang et al., 2010; Zhang et al., 2012) and hnRNP A1 has been postulated to stabilize p16 ${ }^{I N K}$ mRNA (Zhu et al., 2002), but this has not been tested. To this end, we treated HFFs with siRNA to hnRNP A1 and used Actinomycin D to assess stability of p16 $16^{\text {INK }}$ transcripts. Loss of hnRNP A1 (Figure 6-figure supplement 3 ) stabilized both $p 16^{I N K}\left(t_{1 / 2}-2.1\right.$ in control vs 12.3 after HNRNP A1 knockdown) and $p 14^{A R F}$ mRNAs ( $t_{1 / 2}-1.5$ in control vs 6.9 after hnRNP A1 knockdown) but not those of E2F1 or MYC (Figure 6 B). Half-life estimates were obtained as described for panel $A$ and the best fit lines, their equations and $\mathrm{R}$ values are shown in Figure 6-figure supplement $3 B$. The differences in control half-lives between Figure $\mathbf{6 A}, B$ are likely attributable to the different treatments used: in $A$, control cells were transfected with pcDNA3.1 plasmid, while in B, control cells were transfected with 

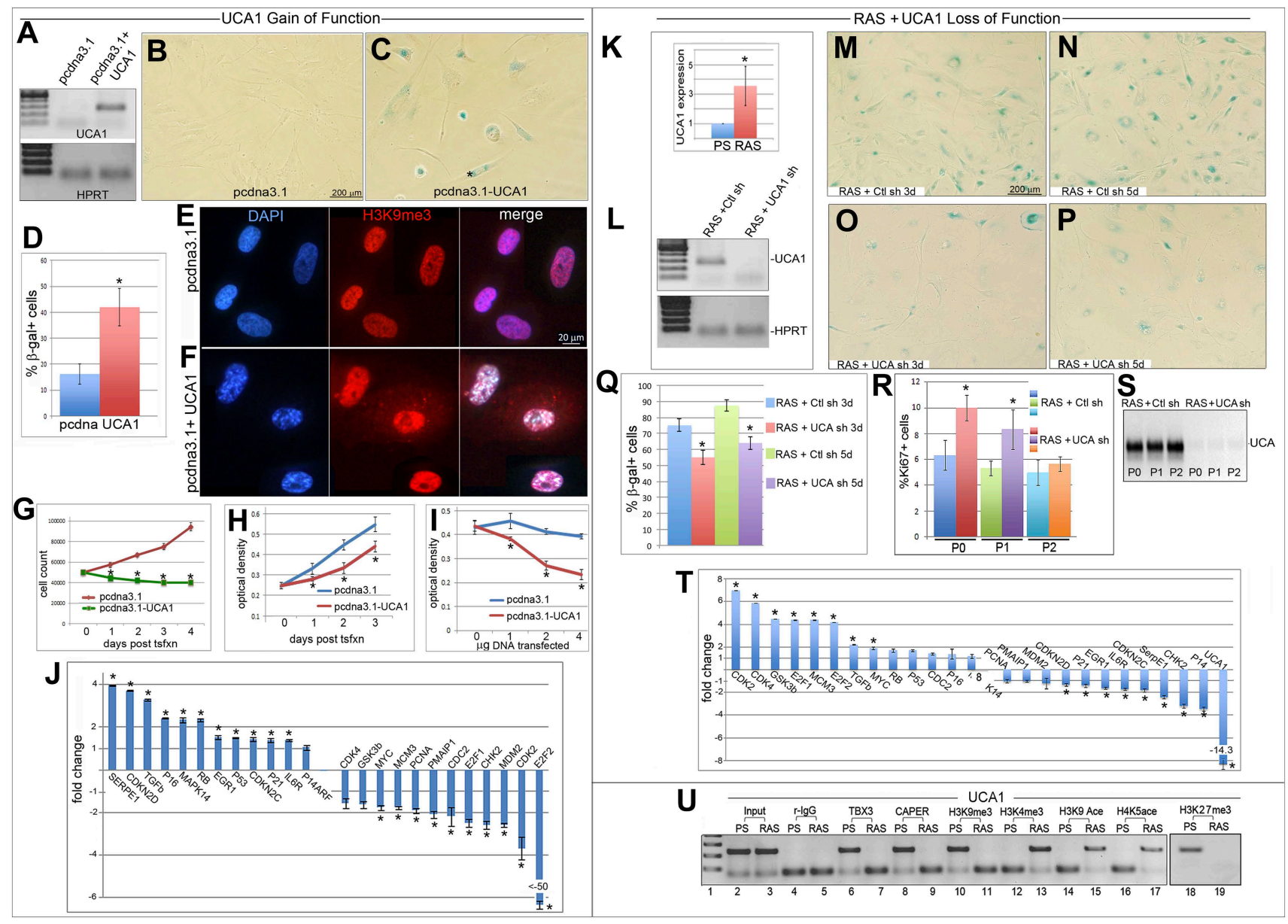

Figure 5. UCA1 expression is sufficient to induce senescence and required for normal execution of oncogene-induced senescence. (A) UCA1 and HPRT transcripts assessed by RT-PCR in control and UCA1-overexpressing HFFs. (B and C) Representative bright field images of SA- $\beta$ gal assay of cultured HFFs transfected with control and UCA1 overexpression plasmids. (D) \% quantitation of SA- $\beta$ gal cells from five replicates in control and UCA1 overexpressing HFFs. * indicates $\mathrm{p}<0.05$. (E and F) Immunohistochemical analysis reveals co-localization of H3K9me3 and DAPI in SAHFs in HFFs transfected with UCA1 overexpression plasmid (F) but not control plasmid (E). (G) Cell count of control and UCA1 overexpressing HFFs 3 days post transfection. Mean \pm SD of 3 plates is shown at each time point. * indicates $\mathrm{p}<0.005$ relative to control. $(\mathbf{H})$ Crystal violet assay of cell growth in control and $U C A 1$ overexpressing HFFs transfected with $2 \mu \mathrm{g}$ of expression or control vector and assayed daily for 3 days post- transfection. * indicates $p<0.01$ relative to control. (I) Crystal violet assay of HFFs cultured for 3 days after transfecting $0,1,2$, or $4 \mu \mathrm{g}$ of control or UCA 1 overexpression plasmid. ${ }^{*}$ indicates $\mathrm{p}<0.01$ relative to control. (J) Transcript levels assessed by qPCR; values reflect fold change in UCA1-overexpressing HFFs relative to control after normalization to HPRT levels. * indicates $p<0.05$ relative to control. (K) qPCR analysis of UCA1 expression in untransduced, presenescent (PS) HFFs and HFFs transduced with constitutively active G12VRAS (RAS). * indicates $\mathrm{p}<0.05$ relative to PS. (L) Efficient knockdown of UCA1 transcripts in RAS HFFs with UCA1 shRNA (quantitated in panel T). (M-P) SA- $\beta$ gal assays of RAS HFFs transduced with either control or UCA 1 shRNA at 3 (M and $\mathbf{O}$ ) and 5 (N and $\mathbf{P}$ ) days post transduction. (Q) \% quantitation of SA- $\beta$ gal cells from six replicate experiments as represented in panels $\mathbf{M}-\mathbf{P}$. * indicates $\mathrm{p}<0.001$ relative to control. (R) \% quantitation of Ki67 + cells from three replicates in control vs UCA1 shRNA transduced RAS HFFs. ${ }^{*}$ indicates $p<0.001$ relative to control. (S) RT-PCR for UCA1 transcripts shows persistent knockdown of UCA1 in RAS shRNA cells with increasing passage (P0-P2). (T) qPCR analysis of fold changes in transcript levels of cell cycle and senescence genes after UCA1 shRNA knockdown in RAS HFFs. * indicates p $<0.05$ relative to control. (U) ChIP-PCR analysis of UCA1 region A3 with antibodies listed at top in PS and RAS HFFs. Note gain of activating (H3K4me3, H3K9ace, H4K5ace) and loss of repressive marks (H3K9me3, H3K27me3) at the UCA1 locus after oncogene-induced senescence by RAS. TBX3, CAPER $=$ human; Tbx3, Capera = mouse. DOI: 10.7554/eLife.02805.016

The following figure supplements are available for figure 5:

Figure supplement 1. Western blots showing changes in protein levels in response to UCA1 overexpression in HFFs. DOI: 10.7554/eLife.02805.017

Figure supplement 2. ChIP-PCR assay for H3K9 acetylation of known regulatory elements of prosenescence and cell cycle genes whose expression is dyregulated after UCA1 overexpression.

DOI: 10.7554/eLife.02805.018 
A

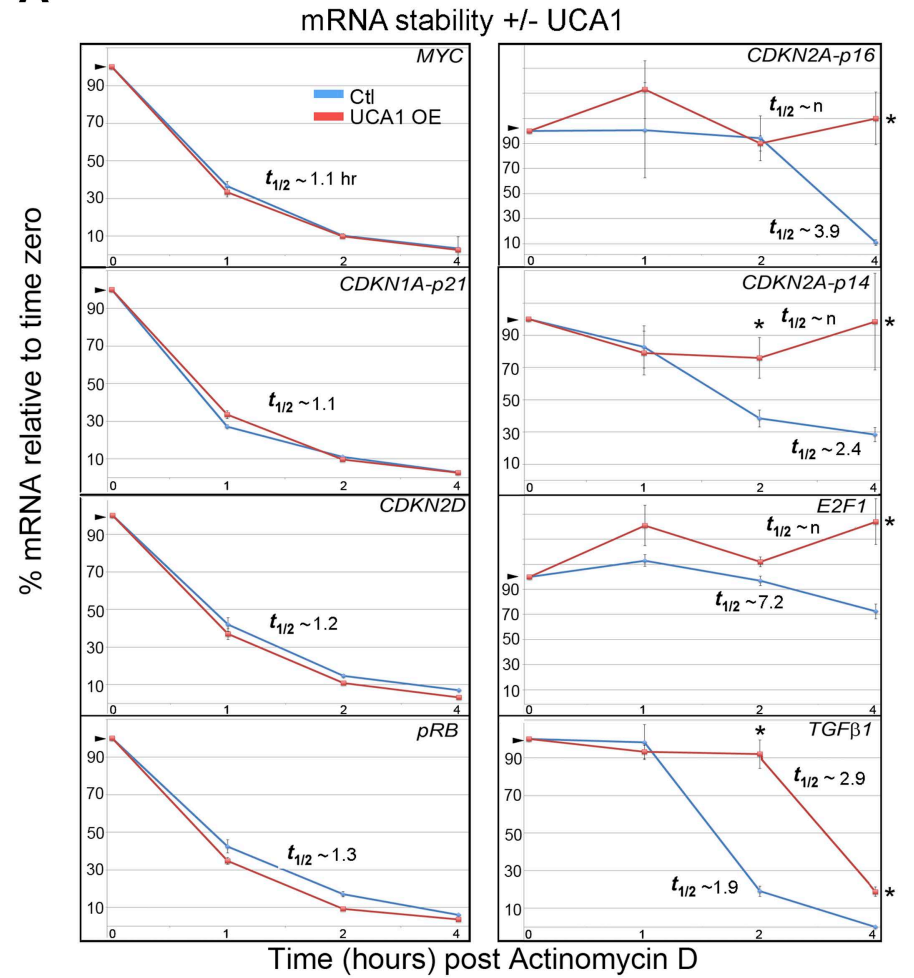

B mRNA stability + /- hnRNP A1

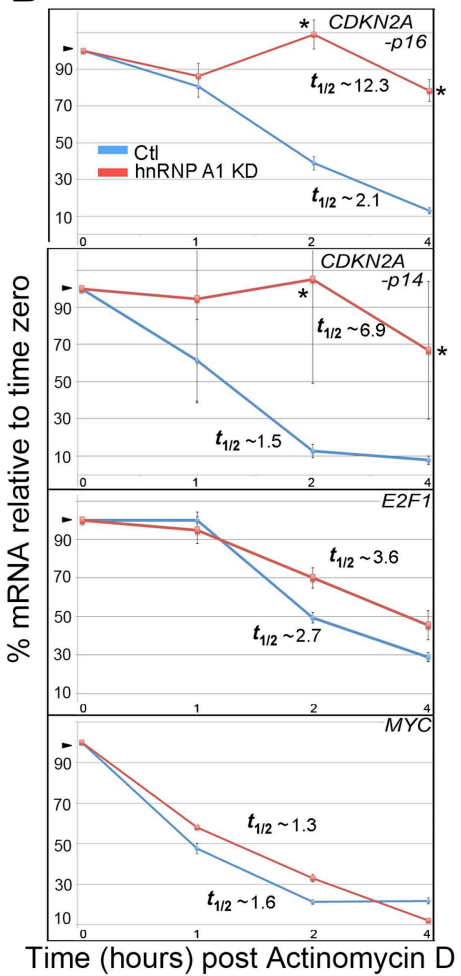

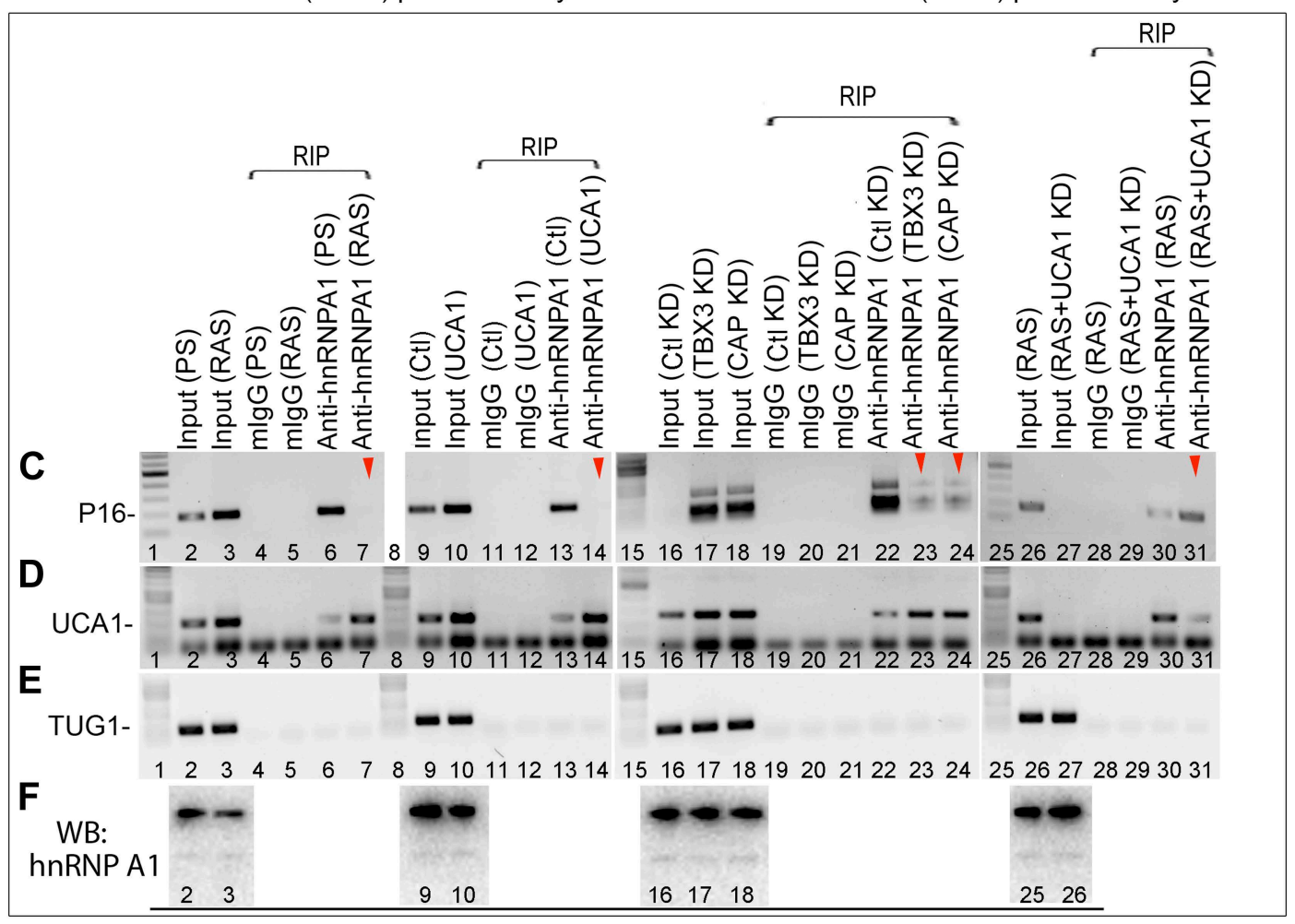

Figure 6. UCA1 stabilizes CDKN2A-p16 mRNA levels during senescence by sequestering hnRNP A1. (A) Graphs of transcript levels assayed by RT-qPCR in HFFs transfected with control (blue) or UCA1 (red) expression plasmids and treated with Actinomycin (D). Y axis shows \% mRNA level relative to time zero and $\mathrm{X}$ axis shows time in hours assayed post treatment. The estimated half-lives $\left(\mathrm{t}_{1 / 2}\right)$ were obtained using linear regression; the best fit lines, their Figure 6. Continued on next page 
Figure 6. Continued

equations and $R$ values are shown in Figure 6-figure supplement 1. * indicates $p<0.04$ for $p 16^{\text {INK }}$ and $p<0.01$ for all others. (B) Assay of mRNA levels in HFFs transfected with control or hnRNPA1 siRNA and treated with Actinomycin D. Axes and $t_{1 / 2}$ calculations are as in panel $\mathbf{A}$. * indicates $p<0.05$. (C-E) Agarose gels of RT-PCR products assessing levels of CDKN2A-p16 (p16, panel C), UCA1 (panel D), and negative control IncRNA TUG1 (panel E) transcripts in PS and RAS HFFs treated as labeled at top and subjected to RIP with anti-hnRNPA1 antibody. mlgG lanes are negative controls for RIP assays. Gels from left to right show: PS vs RAS; control vs UCA1 overexpression; control vs TBX3 or CAPERa knockdown; RAS vs RAS/UCA1 knockdown. (C) Lane 7 (red arrowhead) shows loss of p16 INK /hnRNP A1 interaction in RAS. Lane 14 (red arrowhead) shows loss of p16 INK /hnRNP A1 interaction with UCA1 overexpression. Lanes 23 and 24 show loss of p16 INK /hnRNP A1 interaction after TBX3 or CAPERa knockdown. Lane 27 shows that UCA1 knockdown decreases the total amount of p $16^{\text {INK }}$ mRNA in RAS cells. Lane 31 shows that UCA 1 knockdown increases p $16^{\text {INK }}$ mRNA/hnRNP A1 binding (red arrowhead) in RAS cells, even though there is less total p16 $6^{I N K}$ (lane 27). (F) Panels show immunoblots to detect hnRNP A1 protein in input samples assayed in panels C-E. Lanes are numbered to correspond with panels above. TBX3, CAPER $\alpha=$ human; Tbx3, Capera $=$ mouse.

DOI: 10.7554/eLife.02805.019

The following figure supplements are available for figure 6:

Figure supplement 1. Graphs showing best fit lines, their equations, and R values used to calculate estimated mRNA half-life values shown in Figure 6A. DOI: $10.7554 /$ eLife.02805.020

Figure supplement 2. Northern blot assay of p16 $16^{1 N K}$ mRNA levels in the absence and presence of UCA1. DOI: 10.7554/eLife.02805.021

Figure supplement 3. Graphs showing best fit lines, their equations and R values used to calculate estimated half-life values after hnRNP A1 siRNA knockdown shown in Figure 6B. DOI: 10.7554/eLife.02805.022

Figure supplement 4. RNA Immunoprecipitation analysis of hnRNP A1 interactions with Myc and p14ARF mRNAs. DOI: 10.7554/eLife.02805.023

Figure supplement 5. RIP-PCR of HFF lysates using antibodies listed at top. DOI: 10.7554/eLife.02805.024

Figure supplement 6. RIP-PCR indicates that RB, p21, and CDK6 mRNAs do not interact with hnRNP A1 in PS or RAS HFFs. DOI: 10.7554/eLife.02805.025

control siRNA. The half-life of an mRNA is cell/context specific (as evident in the differences in control half-lives in 6A vs 6B) and in general, cell cycle regulatory genes have short half-lives (Sharova et al., 2009). The $t_{1 / 2}$ of $p 16^{\text {INK }}$ mRNA we observed in HFFs transfected with either control plasmid $\left(t_{1 / 2}-3.9\right)$ or control siRNA ( $\left.t_{1 / 2}-2.1\right)$ is similar to that reported in HeLa cells ( $\left.t_{1 / 2}-2.9\right)$ (Chang et al., 2010). The results we obtained were also similar to those reported for MYC mRNA (Herrick and Ross, 1994; Sharova et al., 2009), CDKN1A mRNA in HT29-tsp53 cells (Melanson et al., 2011) and ES cells (Sharova et al., 2009), and E2F1 mRNA in ES cells (Sharova et al., 2009). The half- lives of Rb and TGF $\beta 1$ are mRNAs extremely variable and those we obtained in HFFs were shorter than reported in ES cells (Sharova et al., 2009).

We next used RNA-IP (RIP) to determine if hnRNP A1 binds $p 16^{\text {INK }}$ and $p 14^{A R F}$ mRNAs in proliferating cells and found that this was indeed the case (Figure 6C, lane 6 and Figure 6-figure supplement 4). Remarkably, hnRNP A1/p16 INK binding was lost in RAS HFFs (Figure 6C, lane 7), despite an overall increase in the number of $p 16^{\text {INK }}$ transcripts (Figure $6 C$, lane 3). As shown previously, UCA1 RNA levels also increase with RAS (Figure 6D, lane 3). UCA1 is bound by hnRNP A1 in PS cells (Figure 6D, lanes 6, 7; Figure 6-figure supplement 5), but unlike p16 ${ }^{\text {INK }}$, the hnRNP A1/UCA1 interaction increases in RAS cells (Figure 6D, lane 7). TUG1 IncRNA serves as a negative control (Figure 6E). Protein levels for hnRNP A1 are shown in Figure 6F. The interaction between UCA1 and hnRNP A1 is specific, as UCA1 does not bind hnRNP K, C1/C2, H, U, or D (Figure 6-figure supplement 5). Although hnRNP A1 binds MYC and p14ARF mRNAs (Figure 6-figure supplement 4), it does not bind $R B, p 21$ or CDK6 mRNAs under the numerous conditions tested (Figure 6-figure supplement 6).

The opposite binding properties of UCA1 and $p 16^{I N K}$ mRNA with hnRNP A1 in PS vs RAS HFFs led us to postulate that UCA1 stabilizes $p 16^{I N K}$ mRNA during OIS by disrupting the interaction between hnRNP A1 and $p 16^{I N K}$ mRNA. In control transfected proliferating cells, there is robust binding of $p 16^{\text {INK }}$ to hnRNP A1 (Figure 6C, lane13), but direct overexpression of UCA1 (Figure 6D, lane 10) or that resulting from TBX3 or CAPERa KD (Figure 6D, lanes 17,18 ) disrupts the hnRNP A1/p16 INK mRNA interaction (Figure 6C, lanes14, 23, 24, red arrowheads). These findings support the hypothesis that loss of hnRNP A1/p16 INK mRNA interaction in OIS (Figure $6 C$, lane 7 ) is the result of increased UCA1 expression and its binding and sequestration of hnRNP A1 (Figure 6D, lane 7). To further test this, we used shRNA to KD UCA1 in RAS HFFs (Figure 6D, lane 27). UCA1 KD restored the interaction between 
hnRNP A1 and p16 $6^{\text {INK }}$ mRNA (Figure $6 C$, lane 31) and led to lower levels of total p16 $6^{\text {INK }}$ mRNA (Figure $6 C$, lane 27), a finding consistent with the negative effects of hnRNP A1/ p16 iNK interaction on stability of $p 16^{I N K}$ transcripts. The effects of UCA 1 on $p 16^{\text {INK }}$ mRNA stability are specific, because hnRNP A1 interactions with MYC or p14 ${ }^{A R F}$ mRNAs are unaffected by UCA1 (Figure 6-figure supplement 1).

In total, these findings indicate that in proliferating cells, the very low quantity of UCA1 transcripts is insufficient to disrupt hnRNP A1/p16 iNK binding, and levels of $p 16^{\text {INK }} \mathrm{mRNA}$ are low due to: (1) direct repression by CAPERa/TBX3 and, (2) p16 INK $\mathrm{mRNA}$ instability conferred by hnRNP A1. When UCA1 levels increase during OIS, by UCA1 overexpression, or via KD of CAPER $\alpha / T B X 3, U C A 1$ binds and sequesters hnRNP A1, preventing it from destabilizing p1 $16^{\text {INK }} \mathrm{mRNA}$.

\section{The CAPER $\alpha / T B X 3$ co-repressor dissociates during oncogene-induced senescence leading to activation of UCA1 and pro-senescence pathways}

Increased p16 protein is required for RAS-induced senescence in MEFS and some human cell types (Serrano et alo, 1997), leading us to determine whether OIS affects CAPERa/TBX3 occupancy of $p 16^{\text {iNK }}$ chromatin. CDKN2A-p16 1/NK genomic regulatory elements bound in PS HFFs (Figure 4I) were not occupied by either TBX3 or CAPER $\alpha$ in RAS HFFs (Figure 7A). Chromatin marks on these regions switched from heterochromatic to euchromatic (Figure 7B, Figure 7-figure supplement 1A). This was also observed with UCA1/A3 (Figure 5U) and DUSP4 chromatin (Figure 7-figure supplement 1B).

We investigated the possibility that altered quantity of either CAPERa or TBX3 could disrupt the stoichiometry of their interaction and cause dissociation from $p 16^{1 N K}$ and UCA1 regulatory elements in OIS. Surprisingly, both TBX3 and CAPERa protein levels were increased in RAS HFFs (Figure 7C), but they no longer co-IP'd (Figure 7D, red box). Immunocytochemistry of endogenous TBX3 and CAPERa in PS and RAS HFFs confirmed increased protein levels in OIS (Figure 7F-M), and revealed dramatic changes in CAPER $\alpha$ localization: CAPER $\alpha$ immunoreactivity became concentrated in large intranuclear foci (Figure $7 L, M$ ), as we previously observed in early passage Tbx3-/- MEFS (Figure 2-figure supplement 2D-F'). These foci are distinct from SAHFs and PML bodies (Figure 7M and Figure 7-figure supplement 2).

To further investigate the molecular basis of senescence initiation after loss of CAPER $\alpha / T B X 3$, we performed genome-wide transcriptional profiling 2 days post CAPER $\alpha$, TBX3 and control KD in HFFs. More than half of the transcripts with expression altered 1.5-fold or more by CAPER $\alpha$ KD were similarly affected by loss of TBX3 ( $N=2375$ CAPER $\alpha$ KD, 2188 TBX3 KD; 1157 co-regulated, $\mathrm{p}<<<<0.0001$, Figure 7-source data 1-3, Figure 7N,O). Gene ontology-biologic process (GO-BP) analysis with DAVID (Huang da et al., 2009a, 2009b) showed highly significant co-regulation of 'transcription regulation' (increased expression) and 'cell-cycle' (decreased expression) transcripts (Figure 7N,0). We tested a subset of these with known roles in senescence by GPCR: $100 \%$ validated and were similarly altered by RAS (Figure 7-figure supplement 3). Further interrogation of this group revealed that IL6 and HDAC9 are CAPERa/TBX3 direct targets and their upregulation in RAS is associated with loss of CAPERa/TBX3 binding (Figure 7-figure supplement 4).

We compared CAPER $\alpha / T B X 3$ co-regulated transcripts to a published data set comparing PS and G12VRAS fibroblasts (Loayza-Puch et al., 2013). This revealed that $11 \%$ of CAPERa/TBX3 up-regulated transcripts were also increased by RAS (Figure $7 \mathbf{N}^{\prime}$ ); among these, GO-BP 'programmed cell death' (31\%) and 'transcription regulation' (34\%) were highly overrepresented. $30 \%$ of CAPERa/TBX3 downregulated transcripts were also in the RAS data set; $>1 / 3$ of these were cell cycle genes (Figure $70^{\prime}$ ). In all comparisons, the number of transcripts common to both groups was greater than predicted by chance and highly statistically significant (Figure 7-source data 3). KEGG pathway analyses revealed overrepresented pathways that were common to both CAPERa/TBX3 and RAS data sets (Figure $7 N-\mathrm{O}^{\prime}$, pie charts), but notably fewer pathways were shared in the upregulated group: JAK/STAT, TLR and TGF $\beta$ signaling pathways were only significantly overrepresented in the CAPER $\alpha / T B X 3$ data set.

\section{Discussion}

Our knowledge of the regulatory mechanisms that govern the onset and maintenance of senescence in different contexts must be considered fragmentary (Wang and Chang, 2011; Fatica and Bozzoni, 2014). In this study, we provide compelling evidence for critical and novel functions of CAPERa, the IncRNA UCA1 and TBX3 in the regulation of cell proliferation and senescence. We have discovered a CAPERa/TBX3 complex that is required to prevent senescence of primary human and mouse cells in 


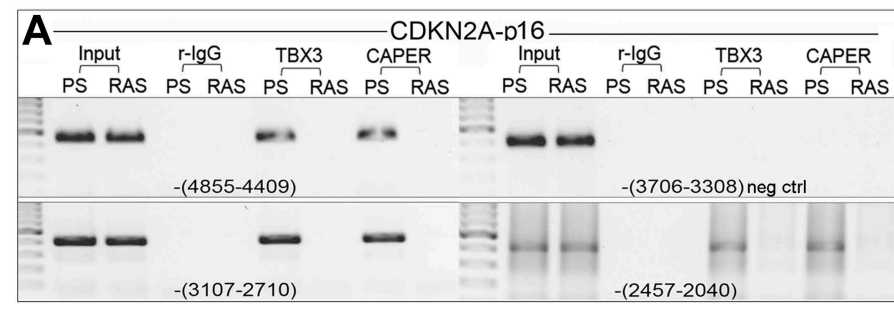

B Input r-lgG H3K9me3 H3K27me3 H2K119ub H3K4me3 PS RAS PS RAS PS RAS PS RAS PS RAS PS RAS
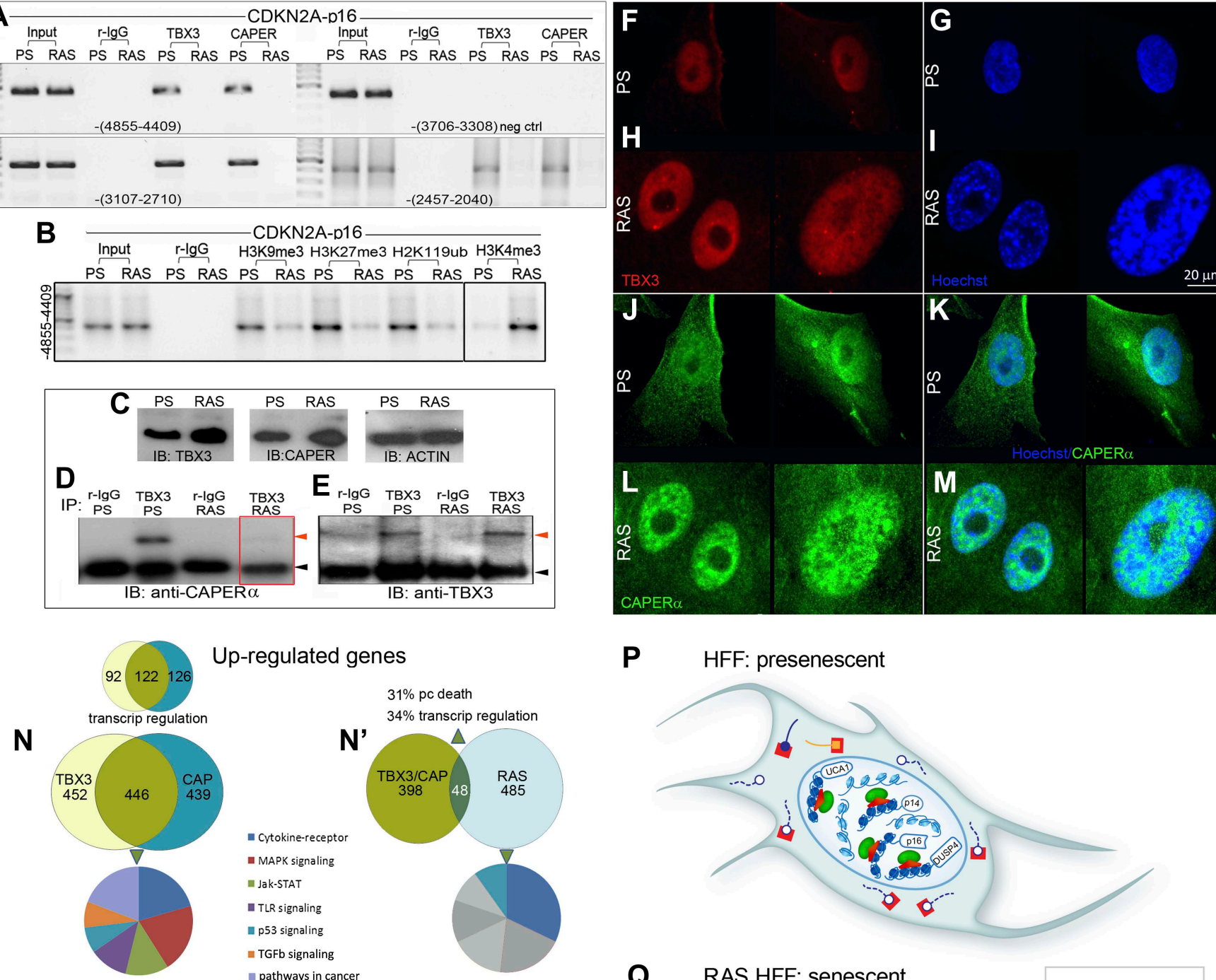

Up-regulated genes
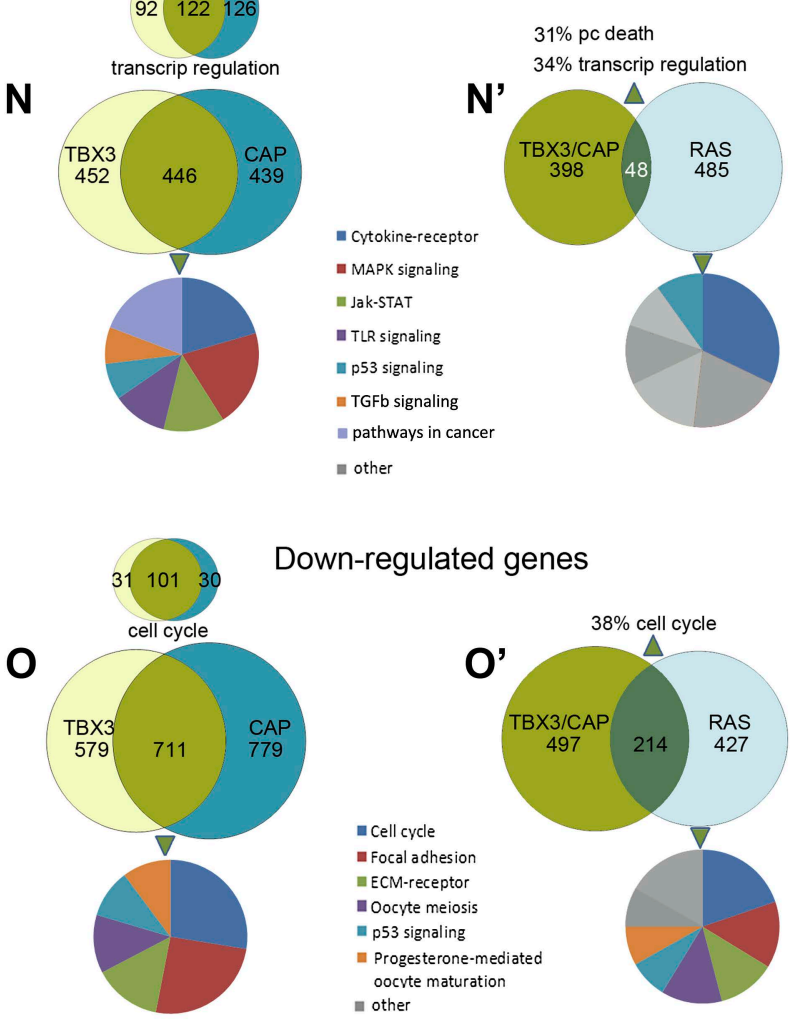

Down-regulated genes
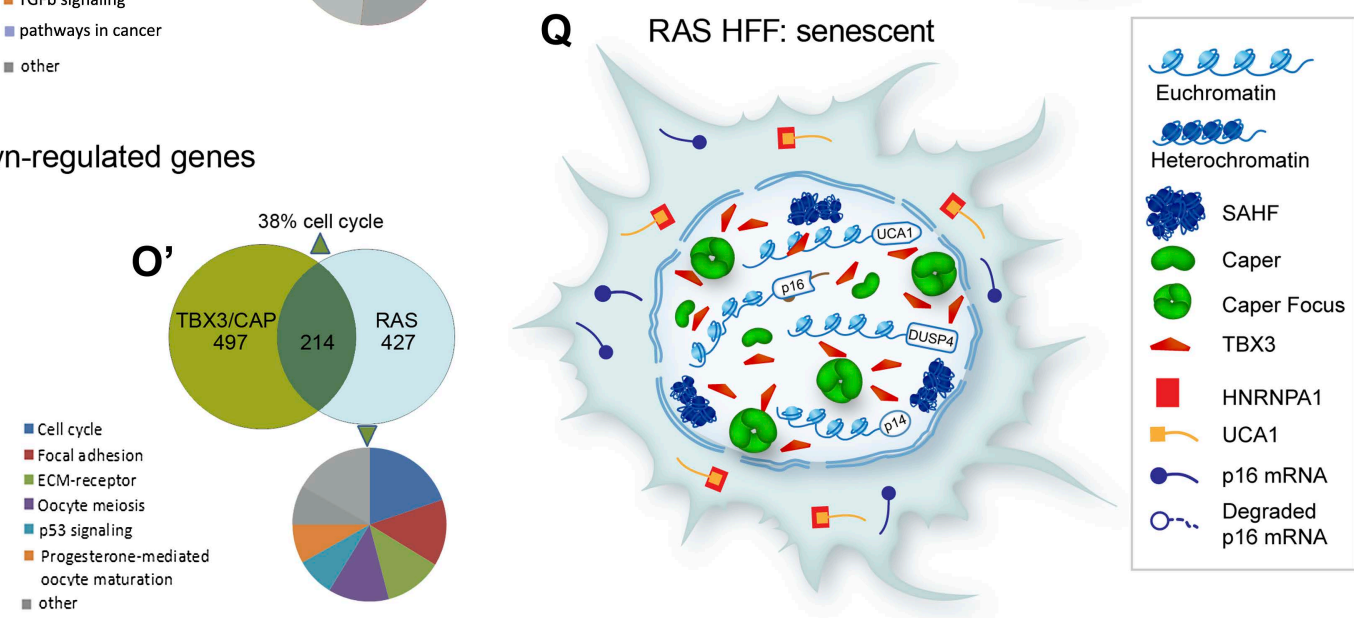

Figure 7. Disruption of the CAPER $\alpha / T B X 3$ repressor by OIS activates CDKN2A-p16 and UCA1 to trigger a senescence transcriptional response. (A) ChIP-PCR of regions upstream of the CDKN2A-p16 transcriptional start site (position relative to TSS in parentheses) in PS and RAS HFFs; the --3706-3308 amplicon is a negative control. OIS disrupts binding of p16 regulatory elements (initially identified in Figure 30) by TBX3 and CAPERa. (B) ChIP-PCR of p16 -4855 element shown in A. Decreased TBX3 and CAPERa binding in RAS correlates with loss of repressive chromatin marks and gain of activating Figure 7. Continued on next page 
Figure 7. Continued

marks. Evaluation of chromatin marks on the other CDKN2A-p16 CAPERa/TBX3- responsive regulatory elements is shown in Figure 7-figure supplement 1A. (C) IBs for TBX3, CAPERa, and actin loading control show increased amount of both proteins in RAS compared to PS HFFs. (D) Anti-TBX3 and anti-CAPERa IBs of IP'd proteins from PS and RAS HFFs. (F-M) Immunocytochemical staining of PS (F, G, J, K) and RAS (H, I, L, M) HFFS for TBX3 $(\mathbf{F}$ and $\mathbf{H})$, Hoechst (DNA; $\mathbf{G}$ and $\mathbf{I})$, CAPER $\alpha(\mathbf{J}$ and $\mathbf{L})$. Panels $\mathbf{K}$ and $\mathbf{M}$ are merged Hoechst/CAPER $\alpha$. Scale bar for all panels is sown at lower right of panel I. (N-O') Functional analyses of genome wide transcriptional profiles of TBX3 KD, CAPERa KD, and control HFFs. All comparisons were statistically significant with $p$ values $<<<<0.0001$; see Figure 7-source data 3 for hypergeometric test, as implemented in the R statistical language, used to test significance of the number of genes found to be co-regulated between samples. (N) Venn diagrams show highly significant number of CAPERa/TBX3 co-upregulated transcripts (446 total), especially in the GO biologic process (BP) category of transcriptional regulation (122 transcripts) as assayed with DAVID. Pie chart shows KEGG pathway analysis of co-regulated genes. (N') Venn diagram showing 48 CAPERa/TBX3 co-upregulated transcripts also upregulated by RAS/OIS (Loayza-Puch et al., 2013), especially in BP categories of transcriptional regulation and programmed cell (pc) death. qPCR validation of coregulated genes is in $\mathbf{S}$. Figure 6A. Pie chart shows KEGG pathway analysis of OIS dataset. ( $\mathbf{O}$ and $\left.\mathbf{O}^{\prime}\right)$ As in $\mathbf{N}$ and $\mathbf{N}^{\prime}$ but for downregulated genes. Pie chart in $\mathbf{O}^{\prime}$ shows KEGG pathway analysis of OIS data set; note most pathways are the same as in TBX3/CAPERa. (P and $\mathbf{Q}$ ) Models of CAPERa/TBX3 repressor and UCA1 function in proliferating (PS) HFFs vs RAS HFFs. In PS cell nuclei, CAPERa/TBX3 represses UCA1, p16, p14, and DUSP4 promoters in heterochromatin which permits ongoing cell proliferation. RAS disrupts the CAPERa/TBX3 complex and CAPER $\alpha$ relocates to dense intranuclear foci. Pro-senescence genes including UCA1 and p16 are converted to euchromatin and their expression/products induce senescence. In the cytoplasm of PS cells, hnRNP A1 binds and destabilizes p16 mRNA, but activation of UCA1 expression in OIS allows UCA1 to sequester hnRNP A1 and stabilize $p 16$ mRNA. TBX3, CAPER $\alpha=$ human; Tbx3, Caper $\alpha=$ mouse.

DOI: 10.7554/eLife.02805.026

The following source data and figure supplements are available for figure 7:

Source data 1. Differentially expressed genes after knockdown of CAPERa in HFFs detected by RNA-Seq. DOI: 10.7554/eLife.02805.027

Source data 2. Differentially expressed genes after knockdown of TBX3 in HFFs detected by RNA-Seq. DOI: 10.7554/eLife.02805.028

Source data 3. Determining the statistical significance of shared differentially expressed genes using the hypergeometric test, as implemented in the R statistical language (phyper).

DOI: 10.7554/eLife.02805.029

Figure supplement 1. Repression of CDKN2A-p16 and DUSP4 by CAPERa /TBX3 correlates with chromatin architecture and is relieved during oncogene induced senescence. DOI: 10.7554/eLife.02805.030

Figure supplement 2. CAPERa relocalization due to oncogene-induced senescence is independent of PML bodies. DOI: 10.7554/eLife.02805.031

Figure supplement 3. Validation of RNA-Seq identified expression changes induced by CAPER $\alpha$ and TBX3 KD. DOI: 10.7554/eLife.02805.032

Figure supplement 4. IL6 and HDAC9 are direct targets of CAPER $\alpha / T B X 3$.

DOI: 10.7554/eLife.02805.033

vivo and that functions as a master regulator of cell proliferation by directly repressing transcription of IncRNA UCA1, p16 INK and other tumor suppressor genes (Figure 7P). Overexpression of UCA1 occurs after loss of TBX3/CAPER $\alpha$ and in OIS (Figure 70), and is itself sufficient to induce senescence at least in part, by disrupting the interaction of $p 16^{I N K}$ mRNA with hnRNP A1 leading to increased $p 16^{\text {INK }}$ mRNA stability (Figure 7P,Q). Disrupting the CAPERa/TBX3 complex by decreasing the amount of either TBX3 or CAPER $\alpha$, or by CAPER $\alpha$ mislocalization during OIS, coordinately increases activity of multiple prosenescence targets at both the transcriptional and post-transcriptional levels in a reinforcing mechanism.

Increased CAPER $\alpha$ has been reported in human breast cancers and a shift from cytoplasmic to nuclear localization correlates with transition from pre-malignant to malignant lesions (Mercier et al., 2009). In contrast, CAPERa co-activates vRel mediated transcription but inhibits vREL transforming activity in vitro (Dutta et al., 2008). It is likely that anti- or pro- oncogenic activity of CAPER $\alpha$ is determined by cell type and the interacting protein(s) present in a given context; our results suggest that CAPER $\alpha$ has oncogenic potential in primary cells since loss of CAPERa/TBX3 induces premature senescence, a vital tumor suppressor mechanism. CAPER $\alpha$ binds to regulatory chromatin domains via TBX3 but dissociates from these domains and becomes concentrated in large intranuclear foci prior to senescence induced by loss of TBX3 or during OIS. Future efforts will define the composition of CAPER + nuclear foci and the role of this nuclear subdomain during senescence induction.

The TBX3 RD is required for TBX3 to interact with CAPERa (this study), immortalize primary fibroblasts and confer senescence bypass (Carlson et al., 2001). Since loss of CAPERa activates target gene transcription despite continued TBX3 occupancy, it is the CAPERa/TBX3 complex (interacting via 
TBX3 RD) that represses pro-senescence target loci. It will be important to determine if previously identified targets of TBX3 transcriptional repression are actually regulated by this complex.

Additional studies are warranted to determine the precise mechanisms whereby histone status is regulated by CAPERa/TBX3: TBX3 is known to interact directly with HDACs (Yarosh et al., 2008), but there are no reports of it or CAPERa interacting with histone methyltransferases or demethylases. Our recently published Mass Spec screen for Tbx3/TBX3 interactors did not identify such factors however, the screen cannot be considered exhaustive as we did not reproducibly detect HDACs or transcription factors previously reported to interact with Tbx3. Future studies to specifically determine whether TBX3 and/or CAPERa interact with, recruit, or modify the function of EZH2, SUV39 and other methyltransferases will be informative.

Previous studies showed that TBX3 represses transcription of p14ARF (upstream of p53) (Bamshad et al., 1997; Fan et al., 2009; Kumar et al., 2014), yet embryonic lethality and mammary phenotypes of Tbx3 mutants are p53-independent (Jerome-Majewska et al., 2005). Our findings reconcile these observations because CAPERa/TBX3 represses $p 16^{\text {INK }}$, the p16/RB pathway is activated in Tbx3-/embryos, and knockdown of either RB or p16 (but not p53) prevents senescence after loss of CAPERa/ TBX3. Furthermore, Tbx3-/- and Cdk2-/-;Cdk4-/- mutant embryos share multiple phenotypes including RB hypo-phosphorylation, reduced E2F-target gene expression, decreased proliferation and premature senescence of MEFs (Berthet et al., 2012; Frank et al., 2012, 2013). Our discoveries of multiple CAPERa/TBX3 binding sites across the CDKN2A locus, and altered chromatin marks after TBX3 and CAPER $K D$, indicate that the complex directly represses transcription by regulating chromatin structure. In total, the data conclusively demonstrate that p16 elevation, CDK2 and CDK4 downregulation, and RB hypophosphorylation mediate senescence downstream of CAPER $\alpha / T B X 3$ loss of function in primary human cells and Tbx3 null mutant embryos. When combined with the pleiotropic effects of CAPERa/TBX3 on UCA1, DUSP4, IL6, HDAC9 and other pathways, it is clear why loss of this repressor induces senescence.

TBX3 may function in nuclear organization and structure: severe changes in nuclear morphology and mislocalization of both CAPERa and lamin $\beta 1$ are apparent in Tbx3-/- MEFs after just one passage, prior to other signs of senescence. Progeria is a rare disease in which LMNA mutations induce cellular and organismal senescence in part by altering stoichiometry and interactions of type $A$ and $B$ Lamins. Progeria fibroblasts have decreased expression of TBX3, TBX3 interacting proteins, and TBX3 targets (Csoka et al., 2004). LMNß1 is a TBX3 interacting protein (Kumar et al., 2014) and expression of $L M N A, L M N \beta 1$, and $L M N \beta 2$ is disrupted by TBX3/CAPERa KD (Figure 7-source data 1-3 and Figure 7-figure supplement 3). TBX3 may regulate $L M N$ gene expression and physically interact with Lamins to influence nuclear homeostasis.

There are many downregulated genes common to the senescence responses triggered by RASG12V and loss of CAPER $\alpha / T B X 3$ however, upregulated transcripts and pathways are largely distinct (Figure $7 N^{\prime}$ ). This is likely attributable to the presence of direct targets of CAPERa/TBX3 repression in the upregulated data set. It will be informative to determine which Jak-STAT, TLR, and TGF $\beta$ pathway members (Figure $7 \mathrm{~N}$ ) are direct CAPERa/TBX3 targets, as the complex roles of these pathways in the senescence associated secretory phenotype, inducing or enforcing autocrine and paracrine senescence, and tumor progression are emerging (Hubackova et al., 2010; Senturk et al., 2010; Hubackova et al., 2012; Davalos et al., 2013).

Recent discoveries of the pervasive functions of IncRNAs as 'signals, decoys, guides and scaffolds' (Wang and Chang, 2011), conferred by their ability to interact with other nucleic acids and as protein ligands, has added new layers of complexity to regulation of transcriptional and post-transcriptional gene expression and translation. Although there has been a logarithmic increase in studies exploring IncRNA expression and activity, potential senescence-regulating activities are still largely unexplored. LncRNA HOTAIR functions as a scaffold to regulate ubiquitination of Ataxin-1 and Snurportin-1 to prevent premature senescence (Yoon et al., 2013). Global alterations in IncRNA expression have been reported in association with replicative senescence (Abdelmohsen et al., 2013), and telomere-specific IncRNAs that regulate telomere function during this process have been identified (Yu et alo, 2014). As this manuscript was in revision, regulation of H4K20 trimethylation of rRNA genes by interaction of quiescence-induced IncRNAs PAPAS and Suv4-20h2 was reported (Bierhoff et al., 2014). To our knowledge, UCA1 is the first IncRNA sufficient to induce senescence.

UCA 1 is expressed in bladder transitional cell carcinomas (Wang et al., 2006) and influences tumorigenic potential of bladder cancer cell lines (Wang et al., 2008; Yang et al., 2012). A very recent 
study identified hnRNP I as a UCA1 interacting protein that stabilizes UCA1 RNA; this interaction was postulated to decrease translation of p27 to support growth of the MCF7 breast cancer line (Huang et al., 2014). In contrast, our results support a tumor suppressor/prosenescence function for UCA1 in primary cells. UCA1 increases stability of $p 16^{I N K}$ mRNA by sequestering hnRNP A1, employing a decoy mechanism that is in some aspects reminiscent of IncRNA PANDA sequestering NF-YA transcription factor to prevent activation of proapoptotic p53 targets and promote cell cycle arrest in the DNA damage response (Wang and Chang, 2011). In the case of UCA1 and hnRNP A1 however, the sequestration has a very specific effect: even though UCA1 expression stabilizes (and hnRNP A1 destabilizes) both $p 16^{\text {INK }}$ and $p 14^{A R F}$ mRNAs (Figure $6 A, B$ ), UCA1 only disrupts the association of hnRNP A1 with p16 $6^{\text {INK }}$ mRNA (Figure $6 \mathrm{C}$ and Figure 6-figure supplement 4). In proliferating cells, abundant hnRNP A1 binds with $p 16^{\text {INK }}$ mRNA resulting in $p 16^{\text {INK }}$ degradation. In senescing cells, $p 16^{\text {INK }}$ mRNA levels increase via reinforcing mechanisms of increased transcription and stability: loss of CAPERa/TBX3 activates transcription of $p 16^{I N K}$ and UCA 1 , in turn, UCA 1 sequesters hnRNPA1.

We recognize that the systems we employed (primary HFFs, mouse embryos and MEFs), while very informative models, provide limited information directly applicable to aging or tumorigenesis without further experimentation. Our data support an important role for CAPERa/TBX3 in regulation of senescence in developmental contexts and, since the CAPERa/TBX3 complex regulates known critical tumor suppressors and there is an increasing literature supporting roles for both TBX3 and CAPERa in tumor biology, this is another worthy area for future investigation. As noted above, expression of CDKN2A-p14ARF and CDKN1A-p21 CIP are repressed by TBX2 and TBX3 and this is postulated to confer the ability of overexpressed TBX2 and TBX3 to permit senescence bypass of Bmi1-/- and SV40 transformed mouse embryonic fibroblasts, respectively (Jacobs et al., 2000; Brummelkamp et al., 2002; Prince et al., 2004). Numerous overexpression studies have suggested a role for TBX3 in breast cancer ((Liu et al., 2011) and references therein) and recent papers have reported the tumorigenic and proinvasive effects of overexpressed TBX3 in melanoma cells (Peres et al., 2010; Peres and Prince, 2013) which may derive in part from TBX3 repression of E-cadherin expression (Rodriguez et al., 2008). More relevant to our work on the importance of the CAPERa/TBX3 complex to prevent senescence and regulate cell proliferation are reports that Tbx3 improves the pluripotency of iPS cells (Han et al., 2010) and prevents differentiation of mouse ES cells (Ivanova et al., 2006).

In conclusion, CAPERa/TBX3 acts as a master regulator of cell growth and fate, exerting pleotropic effects by at least two modes of action: (1) regulating chromatin structure and transcription of both coding and non-coding genes and, (2) modulating mRNA stability by altering the association of RNA binding proteins with target transcripts via UCA1. Further exploration will identify tissue-specific UCA1 targets and binding proteins, and determine whether the ability of TBX3 to confer senescence bypass in other contexts requires CAPERa interaction and/or UCA1 repression. Mining the pathways regulated by UCA 1 and CAPERa/TBX3 will reveal factors that control cell proliferation and fate during development and disease and thus constitute novel cancer therapeutic targets.

\section{Material and methods}

\section{Mass spectroscopy}

Mass spectroscopy as in Kumar et al., (2014)

\section{Protein extraction and immunoprecipitation}

Dignam lysates were prepared and incubated for $4 \mathrm{hr}$ at $4^{\circ} \mathrm{C}$ with the appropriate antibody followed by $2 \mathrm{hr}$ at $4^{\circ} \mathrm{C}$ with the pre equilibrated Dynabeads Protein G (Invitrogen). Immune complexes were collected and washed three times with lysis buffer. Pelleted beads were resuspended in 6X Laemmli buffer and subjected to SDS-PAGE analysis followed by immunoblotting with specific antibodies.

Input lanes contain $5 \%$ of protein lysate used for IP; the rest was used in the IP and of the IP'd material, $25 \%$ was loaded onto the gel for immunoblotting.

\section{Antibodies}

Tbx3 (Frank et al., 2012, 2013), TBX3 (SC-17871,MAB10089,A303-098A), CAPERa (A300-291A), GST (SC-33613), LaminB1 (SC-56144), C-Myc (SC-40), R-lgG (SC-2027), m-lgG (SC-2025), Anti-Flag (Sigma, F3165), H3K9me3 (Cell Signaling, 9754), H3K4me3 (Cell Signaling, 9751), H3K27me3 (Cell Signaling, 9733), H3K9ace (Cell Signaling, 9649), H4K5ace (Cell Signaling, 9672), H3K14ace (Cell Signaling, 4353), p-RB -Ser 810--811 (SC-16670), p-RB -Ser 795 (SC-7986), p-RB -Ser 780 (SC-12901), Rb1 
(SC-73598), H3S10P (SC-8656), H2A K119ub (8240S), p21 (SC-756), p53 (Invitrogen 134100), Cyclin D1 (SC-753), Cyclin D2 (SC-754), Cyclin D3 (SC-755), Cyclin E (SC-20648), CDK2 (SC-6248), CDK4 (SC-601) CDK6 (SC-177), hnRNP K (SC-53620), hnRNP C1/C2 (SC-32308), hnRNP H (SC-10042), hnRNP U (SC-32315), hnRNP A2/B1 (SC-53531), hn RNP A1 (SC-32301), and hnRNP D1 (AB-61193).

\section{MBP pull down assay}

Amylose bound MBP and MBP-tagged TBX3 affinity columns were prepared as per the procedure (E8022S, NEB) described in the manufacturer's protocol. These beads were incubated with 5 and $10 \mu \mathrm{g}$ of GST and GST-CAPER at $4^{\circ} \mathrm{C}$ for $8 \mathrm{hr}$. Bound proteins were eluted with reduced glutathione and analyzed by Western blotting with anti-CAPER antibody.

\section{Cell transfection}

Transfections were performed in HEK293 or EBNA-293 cells with Lipofectamine 2000 (Invitrogen) or in Human fibroblasts with X-tremeGENE HP DNA transfection Reagent (Roche) as per the manufacturer's recommendations.

\section{Plasmids}

Wild-type Tbx3 and exon 7 missense, deleted repressor domain (Tbx3 $A R D 1)$, and Tbx3 $\Delta$ NLS were generated by PCR amplification and cloned into pcDNA3.1. C-terminal deletion constructs Tbx3 1-655, Tbx3 1-623, Tbx3 1-565, Tbx3 1-470 were generated by PCR amplification and cloned into pCS2 with an N-terminal Myc tag. Tbx3 L143P and N277D point mutants were kind gifts of Phil Barnett. UCA1 and CAPERa cDNAs were cloned into PCDN3.1 and PQCXIH for over- expression studies, respectively. Sequence of all plasmids was confirmed. Tbx3 L143P and N277D point mutants plasmids were kind gifts of Phil Barnett. Wild-type CAPERa was generated by PCR amplification and then cloned into pQCXIH retroviral vector; sequence was confirmed. Full length UCA1 was amplified by PCR and then cloned into PcDNA3.1 vector; sequence was confirmed.

UCA1 Cloning FP: AGTTGCGGCCGCTGACATTCTTCTGGACAATGAG

UCA1 Cloning RP: TCCTGCGGCCGCTTGGCATATTAGCTTTAATGTAG

CAPERa Cloning FP: CATCGCGGCCGCATGGCAGACGATATTGATATTG

CAPERa Cloning RP: ACGTGGATCCTCATCGTCTACTTGGAACCAGTAG

\section{Immunofluroscence}

E10.5 embryos were harvested in PBS followed by overnight fixation at $4^{\circ} \mathrm{C}$ in $4 \%$ paraformaldehyde and processed for $7 \mu \mathrm{m}$ cryosections. For cell lines, human fibroblasts were cultured on 8-well chamber slides (BD Flacon) and processed for Immunohistochemistry. Immunohistochemistry was performed using primary antibodies listed above and detected using donkey anti-goat or anti-rabbit Alexa fluor 594 (1:500) and goat anti-mouse Alexa fluor 488(1:500) from Invitrogen. Nuclei were stained with Hoechst or DAPI. Slides were imaged with a Nikon ARI inverted confocal microscope at the University of Utah Imaging Core.

\section{Retroviral transduction and selection of stable cells}

shRNA oligonucleotides (see sequences below) were annealed and cloned into the pGFP-B-RS, pRFPC-RS (Origen) vector and PMKO.1 vector. shRNA against luciferase served as a negative control. Hightiter retrovirus was produced by transfection of shRNA retroviral construct along with gag/pol and VSVG encoding plasmids into EBNA-293 cells by lipofectamine 2000 reagent as per the manufacturer's protocol. Virus containing supernatant was collected after $48 \mathrm{hr}$ of transfection and filtered through $0.45-\mu \mathrm{M}$ filters (Fisher 09-720-4). HEK293 or HFFs were incubated with DMEM containing polybrene $(8 \mathrm{mM})$ and $500 \mu \mathrm{l}$ of TBX3 or CAPERa shRNA encoding retrovirus. $24 \mathrm{hr}$ post infection, cells were split to lower densities and blasticidin or puromycin antibiotic selection applied for 2 days. Stably integrated colonies were selected and analyzed for knock down efficiency by western analysis using Tbx 3 or CAPERa antibody.

TBX3 shRNA A: targets TBX3 exon 7

TBX3 shA FP: CCGG GACCATGGAGCCCGAAGAA ttcaagaga TTCTTCGGGCTCCATGGTC TाTTG TBX3 shA RP: AATTCAAAAA GACCATGGAGCCCGAAGAA tctcttgaa TTCTTCGGGCTCCATGGTC TBX3 shRNA B: targets TBX3 exon 5

TBX3 shB FP: CCGG CAGCTCACCCTGCAGTCCA ttcaagaga TGGACTGCAGGGTGAGCTG TाTाTG TBX3 shB RP: AATTCAAAAA CAGCTCACCCTGCAGTCCA tctcttgaa TGGACTGCAGGGTGAGCTG 
CAPERa shRNA A: targets CAPERa (gene name RBM39) exon 5

CAPER $\alpha$ shA FP: CCGG GACAGAAATTCAAGACGTTttcaagagaAACGTCTTGAATTTCTGTCTTTTTG CAPER shA RP: AATTCAAAAA GACAGAAATTCAAGACGTT tctcttgaa AACGTCTTGAATTTCTGTC CAPER $\alpha$ shRNA B: targets CAPER $\alpha$ exon 1

CAPER shB P:CCGG AAAGCAAGAGCAGAAGTCGTAttcaagagaTACGACTTCTGCTCTTGCTTT TTTTTG

CAPER shB RP: AATTCAAAAA AAAGCAAGAGCAGAAGTCGTA tctcttgaa TACGACTTCTGCTCT TGCTTT

The pMKo.1 puro RB and pMKo.1 puro p53 shRNA vectors were a kind gift of William Hahn obtained via Addgene.

pRB shRNA: Addgene \#10670

p53 shRNA: Addgene \#10672

p16 shRNA: Addgene \#22271

Efficacy and specificity of the pRb, p53, and p16 shRNAs was validated with second shRNAs, and these reagents have been used extensively by many investigators in the years since their initial publication (Masutomi et al., 2003; Stewart et al., 2003; Boehm et al., 2005; Haga et al., 2007; Hong et al., 2009; Elzi et al., 2012).

UCA1 shRNA: targets UCA 1 exon 3

UCA1 ShA FP:

GATCCGTTAATCCAGGAGACAAAGAtcaagagTCTTTGTCTCCTGGATTAACTTTTTTGGA

UCA1 ShA RP:

AGCTTCCAAAAAAGTTAATCCAGGAGACAAAGActcttgaTCTTTGTCTCCTGGATTAACG

Senescence associated $\beta$-galactosidase assay

Performed as per the manufacturer's protocol (9860, Cell Signaling).

Population doubling assay/3T5 growth curves (Figure 2E, $F, R$ )

Primary HFFs were plated in a $10-\mathrm{cm}$ dish and transduced with retrovirus. After $24 \mathrm{hr}$, cells were cultured with antibiotic selection (puromycin or blasticidin) for an additional 24-72 hr. On day 0 of the $3 T 5$ growth curve, cells were trypsinized, counted and 500,000 cells were then plated per 10-cm dish. This procedure was repeated every 3 days for 15 days. Population doublings were calculated by $(\log N 1 / \log 2)-(\log N 0 / \log 2) N 1=$ current cell count, NO = Initial cell count. Curves shown in Figure 2 are representative of two independent experiments.

\section{Cell count (Figure 5C)}

Primary HFFs were plated in 6-well dishes and transfected at 70\% confluence. At days noted in the figure, cells were trypsinized and counted using a hemocytometer.

\section{Crystal violet assay/optical density method of cell quantitation}

$5 \times 10^{5}$ cells were plated per well in 6-well tissue culture plates. At times indicated, medium was removed and cells were washed with PBS, and fixed for $10 \mathrm{~min}$ in 10\% formalin solution. Cells were rinsed $5 X$ with distilled water, and then stained with $100 \mu \mathrm{l} 0.1 \%$ crystal violet solution for $30 \mathrm{~min}$, rinsed $5 \mathrm{X}$ in water and dried. Cell-associated crystal violet dye was extracted with $500 \mu \mathrm{l}$ of $10 \%$ acetic acid. Aliquots were collected and optical density at $590 \mathrm{~nm}$ measured. Each point on the curve shown represents three independent plates.

\section{Senescence marker gene expression in TBX3 and CAPER $\alpha$ KD fibroblasts}

Primary HFFs were incubated with TBX3 or CAPERa or Control shRNA encoding retrovirus medium with fresh virus added every $8 \mathrm{hr}$ for $48 \mathrm{hr}$, followed by antibiotic selection for 6 days. 6 days after selection, floating cells were discarded and adherent cells were utilized for senescence associated $\beta$-gal assay or preparation of RNA.

\section{RNA isolation and reverse transcription-PCR analysis}

Total RNA was prepared using the RNeasy RNA isolation kit (Qiagen) or NucleoSpin RNA II Kit (Clontech) and cDNA was synthesized by cDNA EcoDry Premix Double Primed (Clontech) kit. Q-RTPCR was performed with SoFast Evagreen Supermix (Bio-Rad) as per manufacturer's protocol. 


\section{RT-PCR primer sequences}

TBX3: TGAGGCCTTTGAAGACCATG, TCAGCAGCTATAATGTCCATC CAPERa: CGGAACAGGCGTTTAGAGAA, TGGCACTGCTCAACTTGTTC CDK2: GCTTTCTGCCATTCTCATCG, GTCCCCAGAGTCCGAAAGAT CDK4: ACGGGTGTAAGTGCCATCTG, TGGTGTCGGTGCCTATGGGA P21: TCAGAGGAGGCGCCATGT, TGTCCACTGGGCCGAAGA CDC2: GGGGATTCAGAAATTGATCA, TGTCAGAAAGCTACATCTTC MDM2: ACCTCACAGATTCCAGCTTCG, TTTCATAGTATAAGTGTCTTTTT MAPK14: TTCTGTTGATCCCACTTCACTGT, ACACACATGCACACACACTAAC CDKN2C: CAATGGCTCAGTTTTGCTGAATAA, GTAAGATCTGCCTGCCAAAAGC CDKN2B: AACGGAGTCAACCGTTTCGG, TGTGCGCAGGTACCCTGCA P16: CAACGCACCGAATAGTTACG, AGCACCACCAGCGTGTC SerpinE1:CCGGAACAGCCTGAAGAAGTG, GTGTTTCAGCAGGTGGCGC P14ARF: CCCTCGTGCTGATGCTACTG, ACCTGGTCTTCTAGGAAGCGG MCM3: CCTTTCCCTCCAGCTCTGTC, CTCCTGGATGGTGATGGTCT TGFb: AAGGACCTCGGCTGGAAGTG, CCCGGGTTATGCTGGTTGTA EGR1: CCAGGAGCGATGAACGCAAGCGGCATACCAAG, GGAGTACGTGGTGGCCACCGACGG GGACCC E2F1: ATGTTTTCCTGTGCCCTGAG, ATCTGTGGTGAGGGATGAGG E2F2: GGCCAAGAACAACATCCAGT, TGTCCTCAGTCAGGTGCTTG IL6R: CATTGCCATTGTTCTGAGGTTC, AGTAGTCTGTATTGCTGATGTC GSK3b: ACTCCACCGGAGGCAATTG, GCACAAGCTTCCAGTGGTGTT UCA1:GAAATGGACAACAGTACACGCATATGGGGC, CCTGTTGCTAAGCCGATGATACATTACCCT HPRT: GCTGGTGAAAAGGACCTCT, CACAGGACTAGAACACCTGC PCNA: AAGAGAGTGGAGTGGCTTTTG, TGTCGATAAAGAGGAGGAAGC CHK2: CTTATGTGGAACCCCCACCTAC, CAGCACGGTTATACCCAGCA PMAIP1: GTTTTTGCCGAAGATTACCG, CAATGTGCTGAGTTGGCACT MYC: CTCCCTCCACTCGGAAGGA, GCATTTTCGGTTGTTGCTGAT CDKN2D: CAACCGCTTCGGCAAGAC, CAGGGTGTCCAGGAATCCA P53: CCTCACCATCATCACACTGG, TCTGAGTCAGGCCCTTCTGT RB: TGTGAACATCGAATCATGGAA, TCAGTTGGTGGTTCTCGGTC CXCL10: GAAATTATTCCTGCAAGCCAATTT, TCACCCTTCTTTTTCATGTAGCA IFNB1: GAATGGGAGGCTTGAATACTGCCT, TAGCAAAGATGTTCTGGAGCATCTC ATF3: GTTTGAGGATTTTGCTAACCTGAC, AGCTGCAATCTTATTTCTTTCTCGT DUSP2: GGCCTTTGACTTCGTTAAGC, CCACCTCAGTGACACAGCAC CREB5: CGTGCCTCCTTGAAACAAGCCATT, ATGAAACACCAGCACCTGCCTAGA HDAC9: AGTGTGAGACGCAGACGCTTAG, TTTGCTGTCGCATTTGTTCTTT SP140: TGGGTCAGTTTCTTGTTTATCTGC, AGCAGGCTAGAAGCAAGCTC EGR2: TTGGTGCCTTGTGTGATGTAGAC, CTTTCCATAAGGCAACCCATTT HMGA2: GTCCCTCTAAAGCAGCTCAAAA, CTCCCTTCAAAAGATCCAACTG BIRC5: CATGGTAGGTGCAGGTGATG, CATGGTAGGTGCAGGTGATG ASF1: GGTTCGAGATCAGCTTCGAG, CATGGTAGGTGCAGGTGATG WDR66: CCGAGAAGCAACAGGAGAAA, CTGTGTCTCCAAACGGATCA CDC25C: GACACCCAGAAGAGAATAATCATC, CGACACCTCAGCAACTCAG CENPF: CGAAGAACAACCATGGCAACTCG, TTCTCGGAGGATGGTGCCTGAAT LAMA2: AATTTACCTCCGCTCGCTAT, CCTCCAATGTACTTTCCACG LMNB1: AAGCAGCTGGAGTGGTTGTT, TTGGATGCTCTTGGGGTTC LMNB2: GCTCTGACCAGAACGACAAGG, CCAGCATCTTCCGGAACTTG CDC20: TCCAAGGTTCAGACCACTCC, GATCCAGGCCACAGACCATA DUSP5: GCTCGCTCAACGTCAACCTCAACTCGGTG, AGTGGCGGCTGCCCTGGTCCAGCACCACC DUSP4: CCTGGCAGCCATCCCACCCCCGGTTCCCC, GCTGATGCCCAGGGCGTCCAGCATGTCTCTC mTbx3: TGAGGCCTCTGAAGACCATG, TCAGCAGCTATAATGTCCATC mSerpinE1: AGCCAACAAGAGCCAATCAC, GGATTCTCGGAGGGGTAAAG mIL6: GATGGATGCTACCAAACTGGA, CCAGGTAGCTATGGTACTCCAGAA mP21: TCCACAGCGATATCCAGACA, GGCACACTTTGCTCCTGTG 
mCdc2: CTGCAATTCGGGAAATCTCT, TCCATGGACAGGAACTCAAA

mReprimo: CTTACGGACCTGGGACTTTG, CCAGCACTGAATTCATCACG

\section{MEF isolation from WT and Tbx3 null embryos}

All steps were performed under aseptic conditions. Pregnant female mice were euthanized and 13.5-day-old embryos were isolated from the uterus. Embryos were washed in sterile PBS in 60-mm tissue culture dish at room temperature and transferred into 15-ml sterile falcon tube containing $1 \mathrm{ml}$ of $50 \%$ trypsin in DMEM medium. Embryos were minced using fine scissors followed by gentle pipetting with $1 \mathrm{ml}$ pipette tips and dispersed into cell suspensions in $5 \mathrm{~min}$. Suspensions were plated into $10-\mathrm{cm}$ plates in $10 \mathrm{ml}$ of DMEM with $5 \% \mathrm{FBS}$ and penicillin/streptomycin and incubated for $8 \mathrm{hr}$ in $\mathrm{CO}_{2}$ incubator. Culture medium was replaced with fresh medium every day for 3 days. Passage 0 refers to the stage when cell suspension from the embryos was put into cell culture and subsequent passages are numbered.

\section{Chromatin immunoprecipitation (ChIP)}

Performed as per the manufacturer's protocol (9003S, Cell Signaling).

ChIP primers

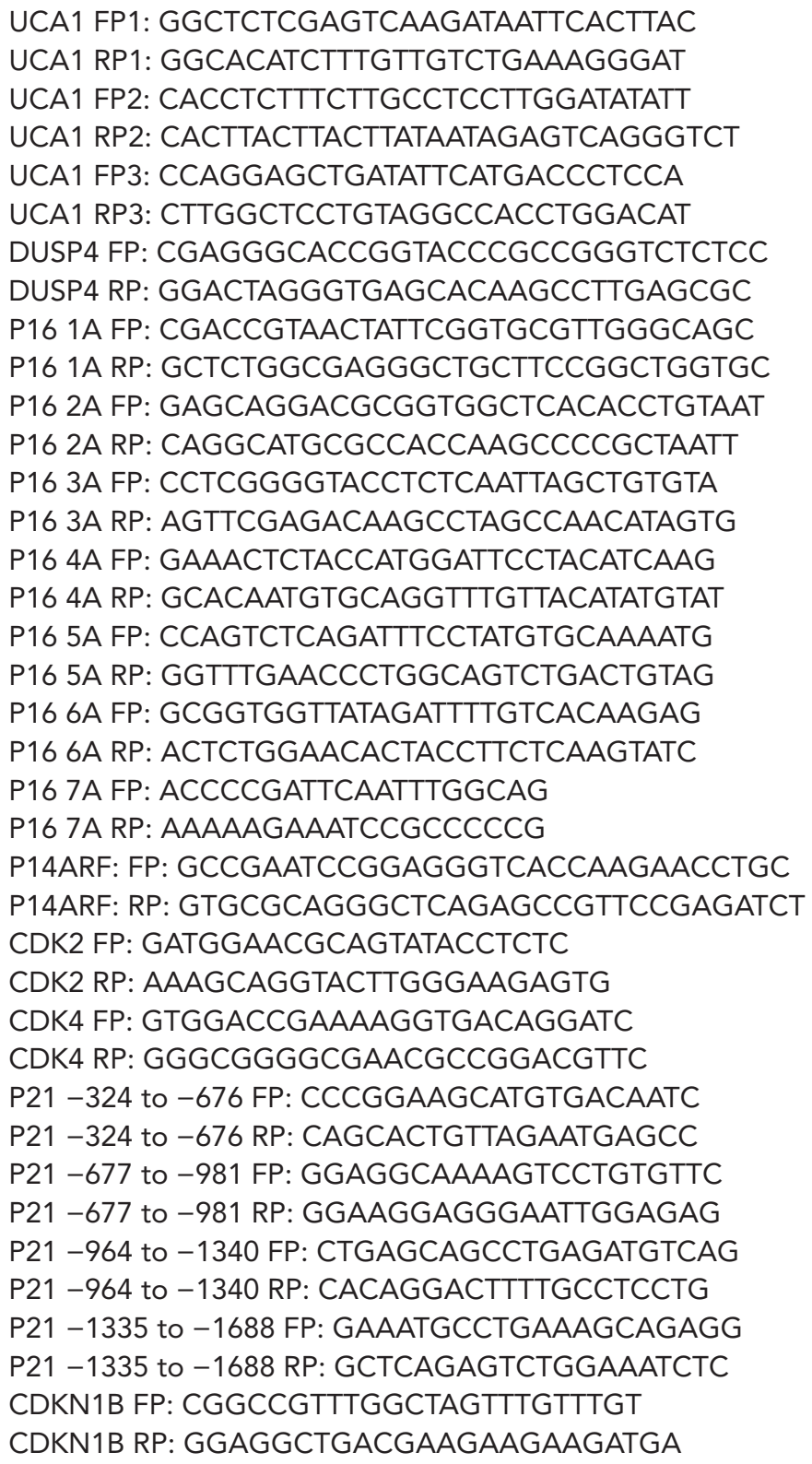




\author{
HDAC9CHIPFP: GGCTCAGGCCGACCATTGTTCTATTTCTGT \\ HDAC9CHIPRP: CCTGAGGAGAAGCAGCAGAGGATCAAC \\ IL6CHIPFP: GAACCAAGTGGGCTTCAGTAATTTCAGG \\ IL6CHIPRP: CATCTGAGTTCTTCTGTGTTCTGGCTCTC \\ P14ARF FP: CCCTCGTGCTGATGCTACTG \\ P14ARF RP: ACCTGGTCTTCTAGGAAGCGG \\ TGFB1 FP: GATGGCACAGTGGTCAAGAGC \\ TGFB1 RP: GAAGGATGGAAGGGTCAGGAG \\ RB FP: GGCGGAAGTGACGTTTTC \\ RB RP: CCGACTCCCGTTACAAAAAT \\ MYC FP: AAGATCCTCTCTCGCTAATCTCC \\ MYC RP: AGAAGCCCTGCCCTTCTC \\ E2F1 FP: GGCTACAGGTGAGGGTCACG \\ E2F1 RP: GAGCGCCGCCACAATTGGCT \\ CDKN2D FP: TCCCTTTCTTCACGGTGCTT \\ CDKN2D RP: GCGTCGCTCCTGATTGGTC \\ CDK2 FP : AAGCAGGTACTTGGGAAGAGTGTTCAGC \\ CDK2 RP: CAACTTGAAACAATGTTGCCGCCTCC \\ MDM2 FP: GGCCTACCCAAAGTGATGGGATTACAAG \\ MDM2 RP: GCCGCTGGAGTTGTACCCAAATGAGTTA
}

\section{siRNA knockdown}

For differential display (Figure 4), HEK293 cells were transfected with control siRNAs (Sense; 5'-CAGCGACUAAACACAUCA-3' Antisense; 5'-UUGAUGUGUUUAGUCGCUGTT-3') or TBX3 specific siRNA A (Sense: GACCAUGGAGCCCGAAGAA, Antisense: UUCUUCGGGCUCCAUGGU) or CAPERaspecific siRNA (Sense: GACAGAAAUUCAAGACGUU, Antisense: AACGUCUUGAAUUUCUGUC) using lipofectamine 2000 (Invitrogen) or X-treme GENE HP DNA transfection reagent as per manufacturer's instructions.

HNRNP A1 siRNA for knockdown in HFFs (Figure 6) was obtained from Cell Signaling (cat. \#7668).

\section{Oncogene-induced senescence with constituitively active RAS}

${ }^{{ }^{1} 12 G}$ RAS virus was produced with $p B A B E-{ }^{112 G} R A S$ as per the procedure described above. HFFs were transduced with RAS virus and incubated with antibiotic selection medium (puromycin $2 \mu \mathrm{g} / \mathrm{ml}$ ) for 4-5 days.

\section{RNA immunoprecipitation (RIP) and RIP-PCR}

For RNA immunoprecipitation, 10 million cells were lysed in $1 \mathrm{ml}$ of NP-40 lysis buffer ( $50 \mathrm{mM}$ Tris $\mathrm{HCl}$, ph7.4, $150 \mathrm{mM} \mathrm{NaCl}, 1 \% \mathrm{NP}-40$ and Protease inhibitor cocktail). Lysate was cleared by centrifugation at $12,000 \mathrm{RCF}$ for $15 \mathrm{~min}$. Cleared lysate was immunoprecipitated independently with $5 \mathrm{\mu g}$ of antihnRNP A1, anti-hnRNP D, Anti-hnRNP A2/B1, Anti-hnRNP C1/C2, Anti-hnRNP K, mlgG and R-lgG antibodies. Immune complexes were incubated with $30 \mu$ of pre-equilibrated Dynabeads for $4 \mathrm{hr}$ at $4^{\circ} \mathrm{C}$. Dynabead purified immune complexes were subjected to Proteinase $\mathrm{K}$ digestion at $37^{\circ} \mathrm{C}$ for $1 \mathrm{hr}$ followed by NucleoSpin RNA II purification kit and cDNA was prepared by RNA-to-cDNA EcoDry Premix kit (Clontech). cDNA was used as a template in PCR amplifications with gene specific primers.

\section{mRNA stability assays}

TBX3, CAPERa, or Control shRNA KD, PS and RAS HFFs were cultured in 6-well culture dishes for 2 days to $80 \%$ confluence. Then Actinomycin $D$ was added to a final concentration of $5 \mathrm{mg} / \mathrm{ml}$ to suppress transcription. At $0,1,2$, and $4 \mathrm{hr}$ after addition of Actinomycin $\mathrm{D}$, equal numbers of cells were harvested from each sample and mRNA was prepared by nucleoSpin RNA II purification kit and cDNA was prepared by RNA-to-cDNA EcoDry Premix kit (Clontech) followed by qRT-PCR for specific transcripts.

\section{P16 INK mRNA northern blot}

HFFs were transfected with pcDNA3.1 control or UCA1 expression plasmids as described above, incubated +/- Actinomycin D, and total cellular RNA was harvested at 0, 1, 2, and $4 \mathrm{hr}$ post treatment. For 
northern blot analysis, $5 \mu \mathrm{g}$ total RNA from each time point was electrophoresed through a $1 \%$ agarose gel. The RNA was blotted onto Hybond-N+ membrane (Amersham Pharmacia), and membranes were UV crosslinked. Membranes were hybridized for $18 \mathrm{hr}$ with (Torres et al., 2003) P-labeled probes. Probes were generated by end-labeling DNA oligonucleotides containing following sequences complementary to $p 16^{\text {INK }}$ mRNA:

1. 5' GAGGAGGTGCTATTAACTCCGAGCATTAGCGAATGTGGC

2. 5' AATCCTCTGGAGGGACCGCGGTATCTTTCCAGGCAAGGGG

3. 5'AAGGCTCCATGCTGCTCCCCGCCGCCGGCTCCATGCTGCT

End-labeling reactions were performed using T4 polynucleotide Kinase (NEB) according to the manufacturer's directions. The hybridized blots were washed, and autoradiographs were developed as per standard procedure. Band intensities were measured by Image J analysis, and densitometric vales were plotted as bar graphs.

\section{RNA-Seq analysis of TBX3 and CAPER $\alpha$ KD HFFs}

HFFs were incubated with TBX3 or CAPER a shRNA encoding retrovirus for $48 \mathrm{hr}$ followed by incubation for an additional $48 \mathrm{hr}$ in selection medium. Total RNA was isolated and purity was assessed. Poly-A RNA was purified, fragmented, primed with random hexamers and used to generate first strand cDNA using reverse transcriptase. Samples that passed quality control steps were used for Illumina library preparation using the Illumina TruSeq RNA Sample Prep protocol. All libraries were sequenced (with barcoding) on a single lane of an Illumina HiSeq instrument for 50 cycles from a single end. A total of 177,155,781 reads were produced in total for all 10 libraries (median 17,348,374 reads). Base calling was performed using Illumina software.

\section{Bioinformatics analysis}

Sequence reads were aligned (98.5\% mapped) to the human genome build 37.2 with Tophat (v2.0.8b) using default parameters. Aligned reads were assembled into transcripts and their relative abundance was measured using Cufflinks (v2.1.1) with fragment bias correction (frag-bias-correct) and multi-read correction (multi-read-correct). Cufflinks transcript assemblies were based on transcripts of NCBI Homo sapiens annotation release 104 and miRBase release 19 as provided in the Illumina iGenomes data set. Cuffdiff was used to test for differential expression between samples and controls and expression differences were taken as significant if the FDR adjusted p-value was less than 0.05 (Source Data Files 1 and 2). Statistically overrepresented gene ontology/biologic process categories and KEGG pathways were determined using DAVID (Huang da et al., 2009a, 2009 b). The hypergeometric test, as implemented in the R statistical language (phyper), was used to test significance of the number of genes found to be co-regulated between samples (Figure 7source data 3).

\section{Acknowledgements}

We thank J Michael Dean and Thomas Vondriska for their support of Drs Kumar and Franklin, respectively. We thank Nikos Tapinos, David Carey, Alana Welm, Kirk Thomas, and Ashley Firment for critical reading of the manuscript. Phillip Barnett kindly provided the Tbx3 DBD mutant plasmids.

\section{Additional information}

Funding

No external funding was received.

Author contributions

PKP, AMM, Conception and design, Acquisition of data, Analysis and interpretation of data, Drafting or revising the article, Contributed unpublished essential data or reagents; UE, Conception and design, Acquisition of data, Contributed unpublished essential data or reagents; RS, Acquisition of data, Analysis and interpretation of data, Contributed unpublished essential data or reagents; SF, BM, Conception and design, Acquisition of data, Analysis and interpretation of data; MY, Bioinformatics, Analysis and interpretation of data, Contributed unpublished essential data or reagents; SLL, Training, Acquisition of data, Analysis and interpretation of data 


\section{References}

Abdelmohsen K, Panda A, Kang MJ, Xu J, Selimyan R, Yoon JH, Martindale JL, De S, Wood WH III, Becker KG, Gorospe M. 2013. Senescence-associated IncRNAs: senescence-associated long noncoding RNAs. Aging Cell 12:890-900. doi: 10.1111/acel.12115.

Baksh S, Widlund HR, Frazer-Abel AA, Du J, Fosmire S, Fisher DE, DeCaprio JA, Modiano JF, Burakoff SJ. 2002. NFATc2-mediated repression of cyclin-dependent kinase 4 expression. Molecular Cell 10:1071-1081. doi: 10.1016/S1097-2765(02)00701-3.

Bamshad M, Le T, Watkins WS, Dixon ME, Kramer BE, Roeder AD, Carey JC, Root S, Schinzel A, Van Maldergem L, Gardner RJ, Lin RC, Seidman CE, Seidman JG, Wallerstein R, Moran E, Sutphen R, Campbell CE, Jorde LB. 1999. The spectrum of mutations in TBX3: genotype/pheotype relationship in ulnar-mammary syndrome. American Journal of Human Genetics 64:1550-1562. doi: 10.1086/302417.

Bamshad M, Lin RC, Law DJ, Watkins WC, Krakowiak PA, Moore ME, Franceschini P, Lala R, Holmes LB, Gebuhr TC, Bruneau BG, Schinzel A, Seidman JG, Seidman CE, Jorde LB. 1997. Mutations in human TBX3 alter limb, apocrine and genital development in ulnar-mammary syndrome. Nature Genetics 16:311-315. doi: 10.1038/ ng0797-311.

Berthet C, Klarmann KD, Hilton MB, Suh HC, Keller JR, Kiyokawa H, Kaldis P. 2006. Combined loss of Cdk2 and Cdk4 results in embryonic lethality and Rb hypophosphorylation. Developmental Cell 10:563-573. doi: 10.1016/j.devcel.2006.03.004.

Bierhoff H, Dammert MA, Brocks D, Dambacher S, Schotta G, Grummt I. 2014. Quiescence-induced LncRNAs trigger H4K20 trimethylation and transcriptional silencing. Molecular Cell 54:675-682. doi: 10.1016/j.molcel.2014.03.032.

Boehm JS, Hession MT, Bulmer SE, Hahn WC. 2005. Transformation of human and murine fibroblasts without viral oncoproteins. Molecular and Cellular Biology 25:6464-6474. doi: 10.1128/MCB.25.15.6464-6474.2005.

Brummelkamp TR, Kortlever RM, Lingbeek M, Trettel F, MacDonald ME, van Lohuizen M, Bernards R. 2002. TBX-3, the gene mutated in ulnar-mammary syndrome, is a negative regulator of p19ARF and inhibits senescence. The Journal of Biological Chemistry 277:6567-6572. doi: 10.1074/jbc.M110492200.

Carlson H, Ota S, Campbell CE, Hurlin PJ. 2001. A dominant repression domain in Tbx3 mediates transcriptional repression and cell immortalization: relevance to mutations in Tbx3 that cause ulnar-mammary syndrome. Human Molecular Genetics 10:2403-2413. doi: 10.1093/hmg/10.21.2403.

Chang N, Yi J, Guo G, Liu X, Shang Y, Tong T, Cui Q, Zhan M, Gorospe M, Wang W. 2010. HuR uses AUF1 as a cofactor to promote p16INK4 mRNA decay. Molecular and Cellular Biology 30:3875-3886. doi: 10.1128/ MCB.00169-10.

Coll M, Seidman JG, Muller CW. 2002. Structure of the DNA-bound T-box domain of human TBX3, a transcription factor responsible for ulnar-mammary syndrome. Structure 10:343-356. doi: 10.1016/S0969-2126(02)00722-0.

Coppé JP, Rodier F, Patil CK, Freund A, Desprez PY, Campisi J. 2011. Tumor suppressor and aging biomarker p16(INK4a) induces cellular senescence without the associated inflammatory secretory phenotype. The Journal of Biological Chemistry 286:36396-36403. doi: 10.1074/jbc.M111.257071.

Csoka AB, English SB, Simkevich CP, Ginzinger DG, Butte AJ, Schatten GP, Rothman FG, Sedivy JM. 2004. Genome-scale expression profiling of Hutchinson-Gilford progeria syndrome reveals widespread transcriptional misregulation leading to mesodermal/mesenchymal defects and accelerated atherosclerosis. Aging Cell 3:235-243. doi: 10.1111/j.1474-9728.2004.00105.x.

Davalos AR, Kawahara M, Malhotra GK, Schaum N, Huang J, Ved U, Beausejour CM, Coppe JP, Rodier F, Campisi J. 2013. p53-dependent release of Alarmin HMGB1 is a central mediator of senescent phenotypes. The Journal of Cell Biology 201:613-629. doi: 10.1083/jcb.201206006.

DeGregori J. 2004. The Rb network. Journal of Cell Science 117:3411-3413. doi: 10.1242/jcs.01189.

Douglas NC, Papaioannou VE. 2013. The t-box transcription factors TBX2 and TBX3 in mammary gland development and breast Cancer. Journal of Mammary Gland Biology and Neoplasia 18:143-147. doi: 10.1007/ s10911-013-9282-8.

Dowhan DH, Hong EP, Auboeuf D, Dennis AP, Wilson MM, Berget SM, O'Malley BW. 2005. Steroid hormone receptor coactivation and alternative RNA splicing by U2AF65-related proteins CAPERalpha and CAPERbeta. Molecular Cell 17:429-439. doi: 10.1016/j.molcel.2004.12.025.

Dutta J, Fan G, Gelinas C. 2008. CAPERalpha is a novel Rel-TAD-interacting factor that inhibits lymphocyte transformation by the potent Rel/NF-kappaB oncoprotein v-Rel. Journal of Virology 82:10792-10802. doi: 10.1128/JVI.00903-08.

Elzi DJ, Song M, Hakala K, Weintraub ST, Shiio Y. 2012. Wnt antagonist SFRP1 functions as a secreted mediator of senescence. Molecular and Cellular Biology 32:4388-4399. doi: 10.1128/MCB.06023-11.

Fan C, Chen Q, Wang QK. 2009. Functional role of transcriptional factor TBX5 in pre-mRNA splicing and Holt-Oram syndrome via association with SC35. The Journal of Biological Chemistry 284:25653-25663. doi: 10.1074/jbc.M109.041368.

Fatica A, Bozzoni I. 2014. Long non-coding RNAs: new players in cell differentiation and development. Nature Reviews Genetics 15:7-21. doi: 10.1038/nrg3606.

Frank DU, Carter KL, Thomas KR, Burr RM, Bakker ML, Coetzee WA, Tristani-Firouzi M, Bamshad MJ, Christoffels VM, Moon AM. 2012. Lethal arrhythmias in Tbx3-deficient mice reveal extreme dosage sensitivity of cardiac conduction system function and homeostasis. Proceedings of the National Academy of Sciences of the United States of America 109:E154-E163. doi: 10.1073/pnas.1115165109.

Frank DU, Emechebe U, Thomas KR, Moon AM. 2013. Mouse tbx3 mutants suggest novel molecular mechanisms for ulnar-mammary syndrome. PLOS ONE 8:e67841. doi: 10.1371/journal.pone.0067841. 
Haga K, Ohno S, Yugawa T, Narisawa-Saito M, Fujita M, Sakamoto M, Galloway DA, Kiyono T. 2007. Efficient immortalization of primary human cells by p16INK4a-specific short hairpin RNA or Bmi-1, combined with introduction of hTERT. Cancer Science 98:147-154. doi: 10.1111/j.1349-7006.2006.00373.x.

Han J, Yuan P, Yang H, Zhang J, Soh BS, Li P, Lim SL, Cao S, Tay J, Orlov YL, Lufkin T, Ng HH, Tam WL, Lim B. 2010. Tbx3 improves the germ-line competency of induced pluripotent stem cells. Nature 463:1096-1100. doi: $10.1038 /$ nature08735.

Hayflick L. 1965. The limited in vitro lifetime of human diploid cell strains. Experimental Cell Research 37:614-636. doi: 10.1016/0014-4827(65)90211-9.

Herrick DJ, Ross J. 1994. The half-life of c-myc mRNA in growing and serum-stimulated cells: influence of the coding and $3^{\prime}$ untranslated regions and role of ribosome translocation. Molecular and Cellular Biology 14:2119-2128.

Hong H, Takahashi K, Ichisaka T, Aoi T, Kanagawa O, Nakagawa M, Okita K, Yamanaka S. 2009. Suppression of induced pluripotent stem cell generation by the p53-p21 pathway. Nature 460:1132-1135. doi: 10.1038/ nature08235.

Hoogaars WM, Barnett P, Rodriguez M, Clout DE, Moorman AF, Goding CR, Christoffels VM. 2008. TBX3 and its splice variant TBX3 + exon 2a are functionally similar. Pigment Cell \& Melanoma Research 21:379-387. doi: 10.1111/j.1755-148X.2008.00461.x.

Huang da W, Sherman BT, Lempicki RA. 2009a. Bioinformatics enrichment tools: paths toward the comprehensive functional analysis of large gene lists. Nucleic Acids Research 37:1-13. doi: 10.1093/nar/gkn923.

Huang da W, Sherman BT, Lempicki RA. 2009b. Systematic and integrative analysis of large gene lists using DAVID bioinformatics resources. Nature Protocols 4:44-57. doi: 10.1038/nprot.2008.211.

Huang J, Zhou N, Watabe K, Lu Z, Wu F, Xu M, Mo YY. 2014. Long non-coding RNA UCA1 promotes breast tumor growth by suppression of p27 (Kip1). Cell Death \& Disease 5:e1008. doi: 10.1038/cddis.2013.541.

Hubackova S, Novakova Z, Krejcikova K, Kosar M, Dobrovolna J, Duskova P, Hanzlikova H, Vancurova M, Barath P, Bartek J, Hodny Z. 2010. Regulation of the PML tumor suppressor in drug-induced senescence of human normal and cancer cells by JAK/STAT-mediated signaling. Cell Cycle 9:3085-3099. doi: 10.4161/cc.9.15.12521.

Hubackova S, Krejcikova K, Bartek J, Hodny Z. 2012. IL1- and TGFbeta-Nox4 signaling, oxidative stress and DNA damage response are shared features of replicative, oncogene-induced, and drug-induced paracrine 'bystander senescence'. Aging 4:932-951.

Imai H, Chan EK, Kiyosawa K, Fu XD, Tan EM. 1993. Novel nuclear autoantigen with splicing factor motifs identified with antibody from hepatocellular carcinoma. The Journal of Clinical Investigation 92:2419-2426. doi: $10.1172 / \mathrm{JCl} 116848$.

Ivanova N, Dobrin R, Lu R, Kotenko I, Levorse J, DeCoste C, Schafer X, Lun Y, Lemischka IR. 2006. Dissecting self-renewal in stem cells with RNA interference. Nature 442:533-538. doi: 10.1038/nature04915.

Jacobs JJ, Keblusek P, Robanus-Maandag E, Kristel P, Lingbeek M, Nederlof PM, van Welsem T, van de Vijver MJ, Koh EY, Daley GQ, van Lohuizen M. 2000. Senescence bypass screen identifies TBX2, which represses Cdkn2a (p19(ARF)) and is amplified in a subset of human breast cancers. Nature Genetics 26:291-299. doi: 10.1038/81583.

Jerome-Majewska LA, Jenkins GP, Ernstoff E, Zindy F, Sherr CJ, Papaioannou VE. 2005. Tbx3, the ulnar-mammary syndrome gene, and Tbx2 interact in mammary gland development through a p19Arf/p53-independent pathway. Developmental Dynamics 234:922-933. doi: 10.1002/dvdy.20575.

Jung DJ, Na SY, Na DS, Lee JW. 2002. Molecular cloning and characterization of CAPER, a novel coactivator of activating protein-1 and estrogen receptors. The Journal of Biological Chemistry 277:1229-1234. doi: 10.1074/ jbc.M110417200.

Kosar M, Bartkova J, Hubackova S, Hodny Z, Lukas J, Bartek J. 2011. Senescence-associated heterochromatin foci are dispensable for cellular senescence, occur in a cell type- and insult-dependent manner and follow expression of p16(ink4a). Cell Cycle 10:457-468. doi: 10.4161/cc.10.3.14707.

Kuilman T, Michaloglou C, Mooi WJ, Peeper DS. 2010. The essence of senescence. Genes \& Development 24:2463-2479. doi: 10.1101/gad.1971610.

Kumar PP, Franklin S, Emechebe U, Hu H, Moore B, Lehman C, Yandell M, Moon AM. 2014. TBX3 regulates splicing in vivo: a novel molecular mechanism for ulnar-mammary syndrome. PLOS Genetics 10:e1004247. doi: 10.1371/journal.pgen.1004247.

Larsson O. 2005. Cellular senescence- an integrated perspective. Cancer Therapy 3:495-510.

Lessnick SL, Dacwag CS, Golub TR. 2002. The Ewing's sarcoma oncoprotein EWS/FLI induces a p53-dependent growth arrest in primary human fibroblasts. Cancer Cell 1:393-401. doi: 10.1016/S1535-6108(02)00056-9.

Lingbeek ME, Jacobs JJ, van Lohuizen M. 2002. The T-box repressors TBX2 and TBX3 specifically regulate the tumor suppressor gene p14ARF via a variant T-site in the initiator. The Journal of Biological Chemistry 277:26120-26127. doi: 10.1074/jbc.M200403200.

Liu J, Esmailpour T, Shang X, Gulsen G, Liu A, Huang T. 2011. TBX3 over-expression causes mammary gland hyperplasia and increases mammary stem-like cells in an inducible transgenic mouse model. BMC Developmental Biology 11:65. doi: 10.1186/1471-213X-11-65.

Loayza-Puch F, Drost J, Rooijers K, Lopes R, Elkon R, Agami R. 2013. p53 induces transcriptional and translational programs to suppress cell proliferation and growth. Genome Biology 14:R32. doi: 10.1186/gb-2013-14-4-r32.

Louie MC, McClellan A, Siewit C, Kawabata L. 2010. Estrogen receptor regulates E2F1 expression to mediate tamoxifen resistance. Molecular Cancer Research 8:343-352. doi: 10.1158/1541-7786.MCR-09-0395.

Masutomi K, Yu EY, Khurts S, Ben-Porath I, Currier JL, Metz GB, Brooks MW, Kaneko S, Murakami S, DeCaprio JA Weinberg RA, Stewart SA, Hahn WC. 2003. Telomerase maintains telomere structure in normal human cells. Cell 114:241-253. doi: 10.1016/S0092-8674(03)00550-6. 
Melanson BD, Bose R, Hamill JD, Marcellus KA, Pan EF, McKay BC. 2011. The role of mRNA decay in p53-induced gene expression. RNA 17:2222-2234. doi: 10.1261/rna.030122.111.

Mercier I, Casimiro MC, Zhou J, Wang C, Plymire C, Bryant KG, Daumer KM, Sotgia F, Bonuccelli G, Witkiewicz AK, Lin J, Tran TH, Milliman J, Frank PG, Jasmin JF, Rui H, Pestell RG, Lisanti MP. 2009. Genetic ablation of caveolin-1 drives estrogen-hypersensitivity and the development of DCIS-like mammary lesions. The American Journal of Pathology 174:1172-1190. doi: 10.2353/ajpath.2009.080882.

Narita M, Nũnez S, Heard E, Narita M, Lin AW, Hearn SA, Spector DL, Hannon GJ, Lowe SW. 2003. Rb-mediated heterochromatin formation and silencing of E2F target genes during cellular senescence. Cell 113:703-716. doi: 10.1016/S0092-8674(03)00401-X.

Peres J, Davis E, Mowla S, Bennett DC, Li JA, Wansleben S, Prince S. 2010. The highly Homologous t-box transcription factors, TBX2 and TBX3, have distinct roles in the oncogenic process. Genes Cancer 1:272-282. doi: 10.1177/1947601910365160.

Peres J, Prince S. 2013. The T-box transcription factor, TBX3, is sufficient to promote melanoma formation and invasion. Molecular Cancer 12:117. doi: 10.1186/1476-4598-12-117.

Prince S, Carreira S, Vance KW, Abrahams A, Goding CR. 2004. Tbx2 directly represses the expression of the p21(WAF1) cyclin-dependent kinase inhibitor. Cancer Research 64:1669-1674. doi: 10.1158/0008-5472. CAN-03-3286.

Rodriguez M, Aladowicz E, Lanfrancone L, Goding CR. 2008. Tbx3 represses E-cadherin expression and enhances melanoma invasiveness. Cancer Research 68:7872-7881. doi: 10.1158/0008-5472.CAN-08-0301.

Saramaki A, Banwell CM, Campbell MJ, Carlberg C. 2006. Regulation of the human p21(waf1/cip1) gene promoter via multiple binding sites for p53 and the vitamin D3 receptor. Nucleic Acids Research 34:543-554. doi: 10.1093/nar/gkj460.

Senturk S, Mumcuoglu M, Gursoy-Yuzugullu O, Cingoz B, Akcali KC, Ozturk M. 2010. Transforming growth factor-beta induces senescence in hepatocellular carcinoma cells and inhibits tumor growth. Hepatology 52:966-974. doi: 10.1002/hep.23769.

Serrano M, Lin AW, McCurrach ME, Beach D, Lowe SW. 1997. Oncogenic ras provokes premature cell senescence associated with accumulation of p53 and p16INK4a. Cell 88:593-602. doi: 10.1016/S0092-8674(00)81902-9.

Sharova LV, Sharov AA, Nedorezov T, Piao Y, Shaik N, Ko MS. 2009. Database for mRNA half-life of 19977 genes obtained by DNA microarray analysis of pluripotent and differentiating mouse embryonic stem cells. DNA Research 16:45-58. doi: 10.1093/dnares/dsn030.

Stewart SA, Dykxhoorn DM, Palliser D, Mizuno H, Yu EY, An DS, Sabatini DM, Chen IS, Hahn WC, Sharp PA, Weinberg RA, Novina CD. 2003. Lentivirus-delivered stable gene silencing by RNAi in primary cells. RNA 9:493-501. doi: 10.1261/rna.2192803.

Torres C, Francis MK, Lorenzini A, Tresini M, Cristofalo VJ. 2003. Metabolic stabilization of MAP kinase phosphatase-2 in senescence of human fibroblasts. Experimental Cell Research 290:195-206. doi: 10.1016/ S0014-4827(03)00309-4.

Wang KC, Chang HY. 2011. Molecular mechanisms of long noncoding RNAs. Molecular Cell 43:904-914. doi: 10.1016/j.molcel.2011.08.018.

Wang C, Hou X, Mohapatra S, Ma Y, Cress WD, Pledger WJ, Chen J. 2005. Activation of p27Kip1 Expression by E2F1. A negative feedback mechanism. The Journal of Biological Chemistry 280:12339-12343. doi: 10.1074/ jbc.C400536200.

Wang F, Li X, Xie X, Zhao L, Chen W. 2008. UCA1, a non-protein-coding RNA up-regulated in bladder carcinoma and embryo, influencing cell growth and promoting invasion. FEBS Letters 582:1919-1927. doi: 10.1016/j. febslet.2008.05.012.

Wang J, Shen WH, Jin YJ, Brandt-Rauf PW, Yin Y. 2007. A molecular link between E2F-1 and the MAPK cascade. The Journal of Biological Chemistry 282:18521-18531. doi: 10.1074/jbc.M610538200.

Wang XS, Zhang Z, Wang HC, Cai JL, Xu QW, Li MQ, Chen YC, Qian XP, Lu TJ, Yu LZ, Zhang Y, Xin DQ, Na YQ, Chen WF. 2006. Rapid identification of UCA1 as a very sensitive and specific unique marker for human bladder carcinoma. Clinical Cancer Research 12:4851-4858. doi: 10.1158/1078-0432.CCR-06-0134.

Yang C, Li X, Wang Y, Zhao L, Chen W. 2012. Long non-coding RNA UCA1 regulated cell cycle distribution via CREB through PI3-K dependent pathway in bladder carcinoma cells. Gene 496:8-16. doi: 10.1016/j.gene.2012.01.012.

Yarosh W, Barrientos T, Esmailpour T, Lin L, Carpenter PM, Osann K, Anton-Culver H, Huang T. 2008. TBX3 is overexpressed in breast cancer and represses p14 ARF by interacting with histone deacetylases. Cancer Research 68:693-699. doi: 10.1158/0008-5472.CAN-07-5012.

Yoon JH, Abdelmohsen K, Kim J, Yang X, Martindale JL, Tominaga-Yamanaka K, White EJ, Orjalo AV, Rinn JL, Kreft SG, Wilson GM, Gorospe M. 2013. Scaffold function of long non-coding RNA HOTAIR in protein ubiquitination. Nature Communications 4:2939. doi: 10.1038/ncomms3939.

Yu TY, Kao YW, Lin JJ. 2014. Telomeric transcripts stimulate telomere recombination to suppress senescence in cells lacking telomerase. Proceedings of the National Academy of Sciences of the United States of America 111:3377-3382. doi: 10.1073/pnas.1307415111.

Zhang X, Liu Z, Yi J, Tang H, Xing J, Yu M, Tong T, Shang Y, Gorospe M, Wang W. 2012. The tRNA methyltransferase NSun2 stabilizes p16INK(4) mRNA by methylating the 3'-untranslated region of p16. Nature Communications 3:712. doi: 10.1038/ncomms1692.

Zhu D, Xu G, Ghandhi S, Hubbard K. 2002. Modulation of the expression of p16INK4a and p14ARF by hnRNP A1 and A2 RNA binding proteins: implications for cellular senescence. Journal of Cellular Physiology 193:19-25. doi: $10.1002 / j c p .10147$. 